MOLECULAR

MAGING

AND BIOLOGY

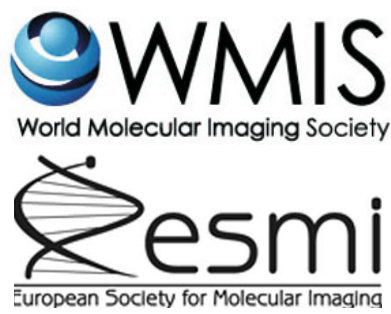

SPECIAL TOPIC

\title{
Advancing Biomarker Development Through Convergent Engagement: Summary Report of the 2nd International Danube Symposium on Biomarker Development, Molecular Imaging and Applied Diagnostics; March 14-16, 2018; Vienna, Austria
}

M. S. Lim, ${ }^{1}$ Thomas Beyer $\odot,{ }^{2}$ A. Babayan, ${ }^{3}$ M. Bergmann, ${ }^{4}$ M. Brehme, ${ }^{5}$ A. Buyx,${ }^{6,7}$ J. Czernin, ${ }^{8}$ G. Egger, ${ }^{7,9}$ K. S. J. Elenitoba-Johnson, ${ }^{1}$ B. Gückel, ${ }^{10}$ A. Jačan, ${ }^{5,11}$ H. Haslacher, ${ }^{12}$ R. J. Hicks, ${ }^{13}$ L. Kenner ${ }^{5,9,14,15}$ M. Langanke, ${ }^{16}$ M. Mitterhauser, ${ }^{7,17}$ B. J. Pichler, ${ }^{18}$ H. R. Salih, ${ }^{19}$ R. Schibli, ${ }^{20}$ S. Schulz, ${ }^{21,22}$ J. Simecek, ${ }^{23}$ J. Simon, ${ }^{7,24}$ M. O. Soares, ${ }^{25}$ U. Stelzl, ${ }^{26}$ W. Wadsak, ${ }^{5,17}$ K. Zatloukal, ${ }^{27}$ M. Zeitlinger, ${ }^{7,28}$ M. Hacker ${ }^{17}$

${ }^{1}$ Department of Pathology and Laboratory Medicine, Perelman School of Medicine, University of Pennsylvania, Philadelphia, PA, USA ${ }^{2}$ QIMP Team, Center for Medical Physics and Biomedical Engineering, General Hospital Vienna, Medical University Vienna, 4L, Waehringer Guertel 18-20, 1090, Vienna, Austria

${ }^{3}$ Department of Tumor Biology, University Medical Center Hamburg-Eppendorf, Hamburg, Germany

${ }^{4}$ Department of Surgery, Surgical Research Laboratories, Medical University Vienna, Vienna, Austria

${ }^{5}$ CBmed - Center for Biomarker Research in Medicine (CBmed GmbH), Graz, Austria

${ }^{6}$ Institute of History and Ethics in Medicine, Technical University Munich, Munich, Germany

${ }^{7}$ Ludwig Boltzmann Institute Applied Diagnostics, Vienna, Austria

${ }^{8}$ Division of Ahmanson Translational Imaging, Department of Molecular and Medical Pharmacology, David Geffen School of Medicine at UCLA, Los Angeles, CA, USA

${ }^{9}$ Department of Pathology, Medical University Vienna, Vienna, Austria

${ }^{10}$ Department of Radiology, Eberhard Karls Universität Tübingen, Tübingen, Germany

${ }^{11}$ Research Unit of Translational Neurogastroenterology, Institute of Experimental and Clinical Pharmacology, Medical University of Graz, Graz, Austria

${ }^{12}$ Department of Laboratory Medicine, Medical University of Vienna, Vienna, Austria

${ }^{13}$ Department of Molecular Imaging, Peter MacCallum Cancer Centre, Melbourne, VIC, Australia

${ }^{14}$ Department of Laboratory Animal Pathology, University of Veterinary Medicine, Vienna, Austria

${ }^{15}$ Christian Doppler Laboratory for Applied Metabolomics, Vienna, Austria

${ }^{16}$ University Medicine Greifswald, Institute for Ethics and History of Medicine, Greifswald, Germany

${ }^{17}$ Division of Nuclear Medicine, Department of Biomedical Imaging and Image-guided Therapy, Medical University of Vienna, Vienna, Austria

${ }^{18}$ Werner Siemens Imaging Center, Department for Preclinical Imaging and Radiopharmacy, Eberhard Karls Universität Tübingen, Tübingen, Germany 
${ }^{19}$ Clinical Collaboration Unit Translational Immunology, German Cancer Consortium (DKTK) and German Cancer Research Center (DKFZ), Partner site, Tübingen, Germany

${ }^{20}$ Department of Chemistry and Applied Biosciences, ETH Zurich, Zurich, Switzerland

${ }^{21}$ Institute for Medical Informatics, Statistics and Documentation, Medical University of Graz, Graz, Austria

${ }^{22}$ Averbis GmbH, Freiburg, Germany

${ }^{23}$ Isotope Technologies Garching GmbH, Garching, Germany

${ }^{24}$ Department of Health Economics, Center for Public Health, Medical University of Vienna, Vienna, Austria

${ }^{25}$ Centre for Health Economics, University of York, York, UK

${ }^{26}$ Diagnostic and Research Center for Molecular Biomedicine, Institute of Pathology, Medical University of Graz, Graz, Austria

${ }^{27}$ Institute of Pathology, Medical University of Graz, Graz, Austria

${ }^{28}$ Department of Clinical Pharmacology, Medical University of Vienna, Vienna, Austria

\begin{abstract}
Here, we report on the outcome of the 2nd International Danube Symposium on advanced biomarker development that was held in Vienna, Austria, in early 2018. During the meeting, cross-speciality participants assessed critical aspects of non-invasive, quantitative biomarker development in view of the need to expand our understanding of disease mechanisms and the definition of appropriate strategies both for molecular diagnostics and personalised therapies. More specifically, panelists addressed the main topics, including the current status of disease characterisation by means of non-invasive imaging, histopathology and liquid biopsies as well as strategies of gaining new understanding of disease formation, modulation and plasticity to largescale molecular imaging as well as integrative multi-platform approaches. Highlights of the 2018 meeting included dedicated sessions on non-invasive disease characterisation, development of disease and therapeutic tailored biomarkers, standardisation and quality measures in biospecimens, new therapeutic approaches and socio-economic challenges of biomarker developments. The scientific programme was accompanied by a roundtable discussion on identification and implementation of sustainable strategies to address the educational needs in the rapidly evolving field of molecular diagnostics. The central theme that emanated from the 2nd Donau Symposium was the importance of the conceptualisation and implementation of a convergent approach towards a disease characterisation beyond lesion-counting "lumpology" for a cost-effective and patient-centric diagnosis, therapy planning, guidance and monitoring. This involves a judicious choice of diagnostic means, the adoption of clinical decision support systems and, above all, a new way of communication involving all stakeholders across modalities and specialities. Moreover, complex diseases require a comprehensive diagnosis by converging parameters from different disciplines, which will finally yield to a precise therapeutic guidance and outcome prediction. While it is attractive to focus on technical advances alone, it is important to develop a patient-centric approach, thus asking "What can we do with our expertise to help patients?"
\end{abstract}

Key words: Biomarker, Health economics, Ethics, Liquid biopsies, Molecular imaging, Molecular and digital pathology, Omics technologies, Patient management, Pharmacology, Theranostics, Treatment, Sample quality

\section{Introduction}

The 2nd Danube Symposium on advanced biomarker development was held over March 14-17, 2018, in Vienna. This symposium was dedicated towards building a framework centred on the philosophy of convergent engagement (http:// news.mit.edu/2011/convergence-0104) of multiple stakeholders in the development and implementation of quantitative, data- driven biomarkers. Multiple definitions for biomarkers exist, but it is understood that reproducible, quantitative and visual biomarkers are required for the practice of personalised diagnosis and treatment $[1,2]$ (Fig. 1).

The 1st Danube Symposium - held in Vienna during September 28-31, 2016 - was one the first of its kind to be specifically devoted to merging complementary expertise in cancer management from molecular pathology, nuclear medicine and clinical 


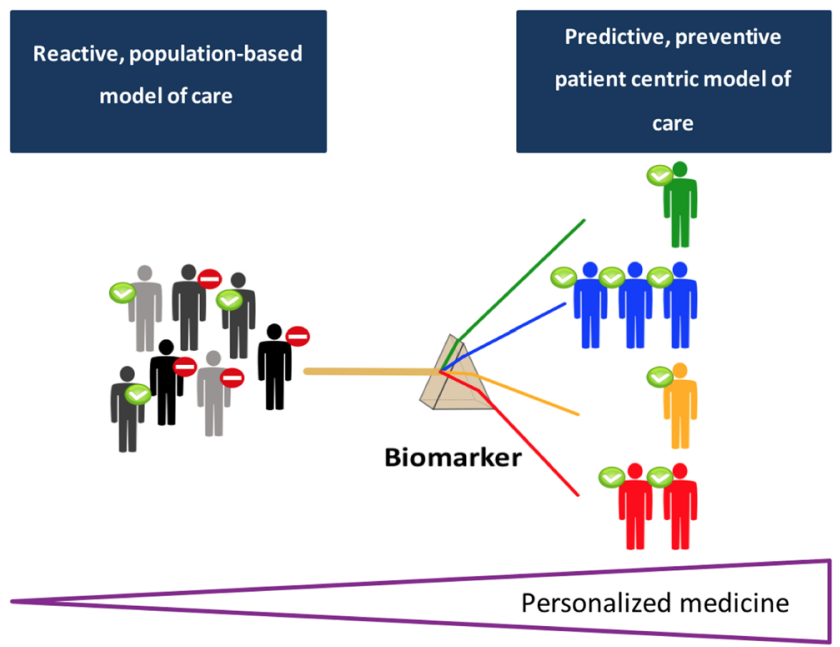

Fig. 1. Illustration of the use of a biomarker as a tool for the development of a predictive, preventive and patient-centric (aka personalised) model of care.

pharmacology. At the time, the programme included a "basic track", which aimed at introducing the partnering specialities - molecular pathology, nuclear medicine and clinical pharmacology, and a "clinical application track" with a focus on prostate cancer. In contrast, the format of the second symposium was modified to provide more in-depth presentation and discussion of different platforms for biomarker identification, development, standardisation and implementation as well as societal and ethical aspects of biomarker-driven personalised medicine (http://www.applied-diagnostics.eu).

The 2018 programme included a series of key presentations, moderated panel discussions, roundtable and rapid-fire presentations the current status of biomarker availability and validity. This included the applicability of liquid biopsies and tissue samples, particularly in light of spatio-temporal tumour heterogeneity as well as access to and sourcing of biobanks. The status of application of existing biomarkers and the development of new compounds for novel therapeutic approaches were also discussed, whereby a particular focus was given to agents targeting the immune system and their translation into the clinic. Finally, a third track brought together panelists who highlighted a frequently under-represented topic: socio-economic and ethical challenges in biomarker development and patient care. Here, we summarise the main topics and outcomes of the discussions. We will indicate progress in key aspects of biomarker-related research as follows: progress ( $\uparrow$ ), steady state $(\leftrightarrow)$ and regression $(\downarrow)$ (Table 1$)$.
The 2018 meeting started with an invited presentation by Dr. Rodney Hicks from the Peter MacCallum Cancer Centre in Melbourne on the "Challenges and Opportunities for Molecular Imaging and Theranostics in the Era of Precision Medicine", which was entitled "Lost in Translation", thus referring to a popular clip (https://www.youtube.com/ watch? $\mathrm{v}=\mathrm{yR}$ (1WICH3rY), that is synonymous of the current state communications between clinicians and researchers in the field of molecular medicine. In essence, similar perspectives were raised by other experts in the field who argued that imaging physicists, for example, need to move beyond simple system engineering and performance measurements towards understanding biology and building their methodological research on biological pre-conditions and clinical questions [3], or who claimed failure in speaking the same language when communicating over the imaging needs for oncology.

Dr. Hicks highlighted how our understanding of oncology has transitioned only recently from the assessment of its morphological characteristics on both imaging and histopathology to detailed genomic interrogation. In view of the human cancer genome programme [4], he argued that it has become clear that, rather than focusing on cancers by their organ of origin, individual genomic drivers are critical to the behaviour and, hence, the prognosis and treatment of specific cancer subtypes. Accordingly, it has become increasingly important to characterise the biological features, indeed the specific genomic drivers of cancer in an individual patient in order to select more specifically targeted therapies that will deliver rational and efficient cancer control. This process has been labelled "precision medicine".

As the oncology community becomes better informed about the hallmarks of cancer, there is an opportunity to leverage these features of biology as both diagnostic and therapeutic targets (http://news.mit.edu/2011/convergence0104). Through imaging, it becomes feasible to identify variations in target expression throughout the body but not the genomic basis of such variation. Tissue and serum biomarkers, on the other hand, can start to deconvolve these processes but cannot localise the site of disease. Biopsy specimens are also limited to assessment of a small portion of the potential disease burden and may not be representative of all disease sites. However, by combining these techniques, it becomes possible to draw links between phenotype and genotype, which must be inextricably linked [5]. This can be performed prior to the onset of treatment in order to

Table 1. Key to current status of biomarker development

\begin{tabular}{ll}
\hline$\uparrow$ & Documented evidence of improvement in science and methodology \\
$\nearrow$ & Suggestion of improvement in methodology, but requires further investigation \\
$\leftrightarrow$ & No change, but satisfactory status since previous workshop \\
$\searrow$ & Little advancement in science and methodology despite previous recognition of need for improvement \\
$\downarrow$ & Less clear evidence than previously suggested \\
\hline
\end{tabular}


optimise therapeutic selection but also early during treatment to assess target modulation.

However, heterogeneity is ubiquitous in cancer and poses a major challenge to any single therapeutic modality. As a consequence, combinatorial therapies will be required. Molecular imaging, targeted biopsy and genomic evaluation of circulating tumour deoxyribonucleic acid (DNA) already provide complementary methods to characterise cancer for selection and sequencing of cancer therapies and will become vital tools for monitoring the response of cancer to therapy and its evolution if not eradicated by initial treatment efforts. He concluded by saying that the opportunity that molecular imaging provides is mainly in identifying non-responding sites of disease as sources of relapse and metastasis, which ultimately lead to lethality of cancers. Therefore, the assessment of the mechanism of resistance in such disease can then be specifically interrogated by either targeted biopsy or the use of liquid biopsy, providing information that might inform alternative or additional treatment options as well as minimally invasive biomarker candidates for diagnostic applications in parallel to imaging approaches.

\section{Tracks}

Building on feedback from the first symposium and ongoing debates in the field, the programme of this second symposium was broken into three serial tracks that highlighted key aspects of biomarker development: disease characterisation (track 1), biomarker handling and treatment (track 2) and, finally, evidence and ethical aspects (track 3).

\section{Track 1: Disease Characterisation}

Disease characterisation on a molecular level and the identification of treatable targets as well as clonal evolution and resistance play an increasingly important role. Modern diagnostic and therapeutic biomarkers are frequently identified from large biobanks containing human tissue or liquid samples or are derived from thousands of clinical data sets, applying bioinformatics or other artificial intelligence (AI) approaches. Novel strategies also focus on the generation of patient-derived cell (PDC) culture, three-dimensional spheroid and organoid avatars from human tissue samples in vitro or humanised mice in vivo [6]. This raises multiple ethical and legal questions that have to be resolved before wider adoption.

The overarching goal of any disease characterisation is to collect a sufficient number of reliable and reproducible data points (aka biomarkers) for a personalised approach to each patient in need of a therapy, the right diagnosis at the right time for the right patient yielding the most efficient treatment (Fig. 1). Until a few years ago, over 150,000 studies have been published that document thousands of claims for promising biomarkers, but only a hundred or so have been validated for clinical use [7]. The reason for this high attrition rate is seen by many as a failure of researchers to embrace a collaborative, systems-based approach to biomarker development. This track aimed at highlighting biomarker diversity in view of the need to harmonise their sourcing with high quality. General progress indicators for biomarker development in disease characterisation are summarised in Table 2.

\section{Liquid Biopsy Versus Tissue Probes Versus Molecular Imaging}

\section{Liquid Biopsy}

The Issues Tumour cells may vary in tissue and genetic composition across lesions within a single patient, and they may change their profile during the course of therapy or monitoring [8-11]. Thus, it has been suggested to analyse circulating tumour cells (CTCs) and tumour-derived products in the context of liquid biopsy [12-14]. Unlike physical fine-needle biopsies, liquid biopsies are quick, minimally invasive and comprehensive in tissue profiling, assuming a high sensitivity and reproducibility of the liquid analysis work-up.

Recent Advances Recent advances allow for application of liquid biopsy tests for early cancer detection [13]. Cohen et al. [15] reported a novel test, enabling detection and localisation of eight most common cancers. Although sensitivity of the test is up to $98 \%$ for ovarian cancer, the average sensitivity of the test was only $70 \%$ with a specificity of $99 \%[15,16]$.

CTC can be characterised as anoikis-resistant, genetically and phenotypically heterogeneous cells with ability to

Table 2. Track 1: progress indicators for biomarker development in disease characterisation

\begin{tabular}{|c|c|c|}
\hline Feature & 2016 & 2018 \\
\hline Clinical adoption of liquid biopsies as indicators of disease onset and cancer therapy response & $\leftrightarrow$ & $\nearrow$ \\
\hline Tissue-based genomic analysis as part of routine patient management & $\downarrow$ & $\downarrow$ \\
\hline Molecular imaging providing sufficiently validated biomarkers & $\searrow$ & $\searrow$ \\
\hline Use of biobanks for large-scale biomarker development & $\searrow$ & $\searrow$ \\
\hline Radiomics for improving early treatment response assessment & $\downarrow$ & $\searrow$ \\
\hline Data mining using electronic health records & $\downarrow$ & $\searrow$ \\
\hline Interactomics as a clinical concept & $\downarrow$ & $\downarrow$ \\
\hline
\end{tabular}


invasion and metastasis-initiating potential [12]. CTC analysis is a validated prognostic test in metastatic breast, colon and prostate cancers [17-19]. Moreover, the presence of CTCs measured at baseline before neoadjuvant therapy is predictive for survival independently from pathological complete response [20]. Besides CTCs, circulating tumour DNA (ctDNA) is another liquid biopsy analytic widely utilised for monitoring of progression and therapy response [13, 21-24]. Among circulating non-coding nucleic acids, miRNAs are the most prominent analytics [25-28].

Future Challenges Biomarkers discovered and validated on cohorts of late-stage patients might be under-represented in early-stage/high-risk individuals [13]. Furthermore, agingassociated appearance of mutations in cancer-associated genes represents another hurdle in application of early detection tests [29]. Challenges in CTC detection are related to biological properties of the cells [30, 31]. Despite recent advances of the development and application of liquid biopsy tests, one of the major issues remains standardisation of the pre-analytical parameters [28].

\section{Tissue Probes and Tissue-Based Genomics}

The Issues In oncology, clinical decision-making is mostly based on laboratory tests and histopathological analyses. Although these techniques are widely used, the total cost adds up to only around $2 \%$ of healthcare costs worldwide. In contrast, lab tests drive around $80 \%$ of total healthcare costs for therapies. Laboratory tests are widely available, easily accessible and highly sensitive. On the other hand, in the context of novel concepts of targeted therapies, implementation of workflows that identify highly specific proof of target structural alterations (mutations) becomes important.

Recent Advances Over the past decade, molecular diagnostic laboratories have moved from single gene assays to large-scale genomic analyses, which allow for more sensitive and simultaneous detection of many gene regions, thus enabling testing of multiple genetic alterations even with limited amounts of starting DNA/RNA. Most laboratories utilise targeted sequencing panels for lower sequencing costs and shorter turn-around times. In addition, targeted sequencing panels allow for higher sequencing coverage of genomic regions of interest, which is critical for the identification of somatic mutations in clinical samples that are typically composed of both neoplastic and non-neoplastic cells. These approaches have been successfully implemented to evaluate gene mutations relevant for "solid tumors" and "hematologic malignancies" using small amounts of starting material, such as fine-needle aspirations [32].

Future Challenges Many potentially targetable genetic alterations are rare and lack sufficient supportive evidence from well-designed clinical trials. A large inter-institutional database would enable healthcare professions to collate and share the molecular and clinical data, as attested by the efforts of the Molecular Analysis for Therapy Choice (MATCH) trial for adults and children supported by the National Cancer Institute, and the Target Agent and Profiling Utilization Registry (TAPUR) trial conducted by the American Society of Clinical Oncology (ASCO) [33].

Furthermore, the role of the tissue pathologist in the implementation and reporting of liquid biopsies needs to be clarified. Figure 2 demonstrates a framework by which various biosamples, molecular testing platforms and their integration may contribute to the clinical decision-making process for patients with lung cancer.

\section{Molecular Imaging: a Non-invasive Tool for Disease Characterisation at the Forefront of Precision Medicine}

The Issues Clinical molecular imaging applications, such as those promoted through positron emission tomography (PET), have been dominated by the relatively non-specific tracer 2-deoxy-2- $\left[{ }^{18} \mathrm{~F}\right]$ fluoro-D-glucose $\left(\left[{ }^{18} \mathrm{~F}\right] \mathrm{FDG}\right)$, a glucose analogue. However, the intrinsic innovation potential of PET is clearly in the ability to fully quantify metabolic and signaling pathways non-invasively [2]. More recently, innovation in PET detector technology and system design has been demonstrated through the introduction of novel detector and readout concepts that helped improve the spatial and temporal resolution as well as the combination of PET with computed tomography (PET/CT) or PET with magnetic resonance imaging (PET/MRI) [34-37]. To date, this innovation path has been seemingly more convincing than that of disease-specific imaging probes ready for routine clinical use, thereby attesting more to rather extreme hurdles along the way of probe validation and market authorisation rather than developing probes that target specific metabolic of signaling pathways.

Recent Advances Over the past decade, radiopharmaceuticals for the diagnosis of Morbus Alzheimer and somatostatin receptor expressing neuroendocrine tumours and prostate cancers have become available [38].

Future Challenges With the advent of costly yet potent immunotherapies, molecular targeted therapies and combinations thereof, the field of cancer diagnostics, disease monitoring and therapy guidance has to undergo a paradigm shift, as supported by multi-modality PET/CT and PET/MR imaging [36, 37].

However, current clinical diagnostic workflows are trimmed towards simplification and often ignore the wealth of quantitative data yielded by PET, including in-depth information about pharmacokinetics [2]. So far, the costs of non-invasive imaging - which is marginal compared to the 


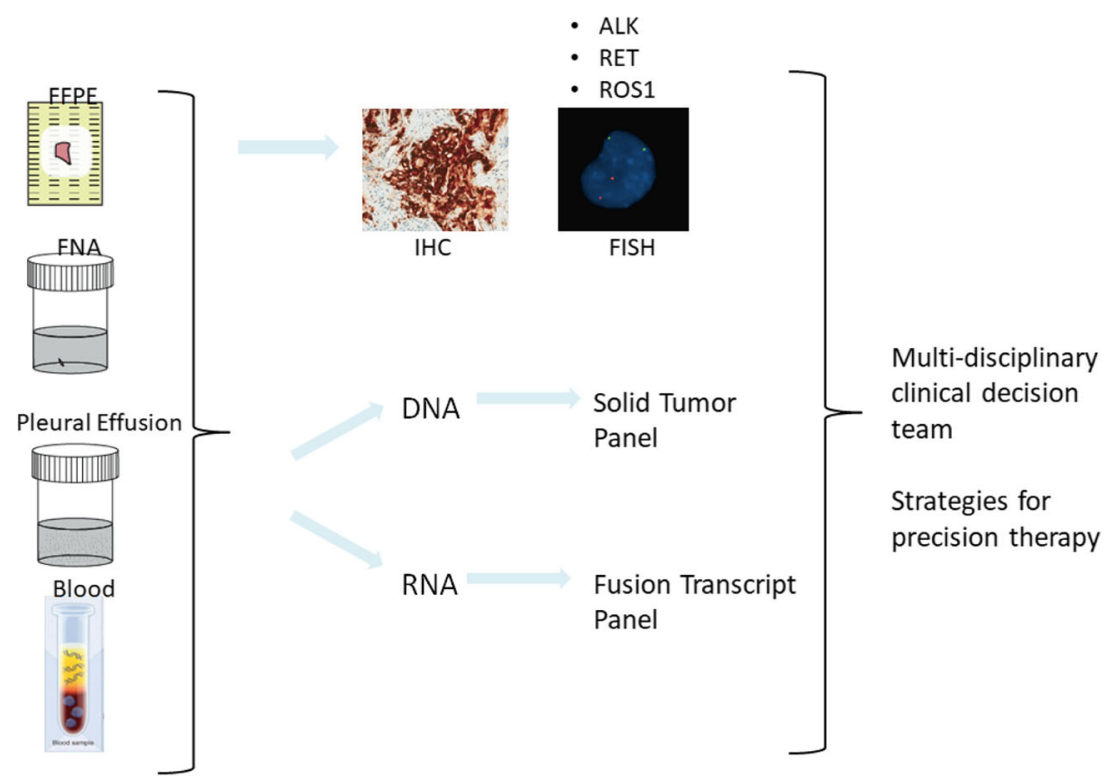

Fig. 2. Framework for multi-modality molecular testing of biospecimens that may be used to identify molecular targets for precision oncology in lung cancer patients. FFPE, formalin-fixed paraffin-embedded; FNA, fine-needle aspiration.

costs of modern combinatorial therapies that can be as high as US $\$ 400,000$ per patient. Unfortunately, the imaging field is not ready yet to provide the desired diagnostic or prognostic information for state-of-the-art and clinically applied immunotherapies (involving checkpoint inhibitors, antibodies or cell-based therapies), molecular targeted therapies or the combination thereof.

\section{Innovation in Biobanking}

\section{The Issues}

To understand the combined effects of genetic and environmental factors on health and diseases, a broad spectrum of samples and analytes has to be investigated by a variety of omics technologies. The development of analytical technologies goes hand in hand with the development of quality requirements of biospecimen in order to guarantee proper test performance and reproducible data. Furthermore, biosamples have to be associated with detailed information on the patient or sample donors, sample-related meta-data as well as data generated by analysis of samples, making data management a core activity of biobanks.

\section{Recent Advances}

The importance of pre-analytical standards has been attested by key features of the European Committee for Standardization (CEN) Technical Specifications, which, following the Vienna Agreement, became International
Organization for Standardization (ISO) standards this year. The European biobanking research infrastructure BBMRIERIC has mapped 60 million biosamples in Europe. A series of the CEN Technical Specifications on sample pre-analytics have been published to standardise sample quality, which is essential for generating reproducible test results. These standards are also relevant in the context of the European Union Regulation "In vitro Diagnostics and Medical Devices" since diagnostic developers have to provide data on pre-analytical sample requirements to guarantee assay performance [39].

Digital histological images are a new and important resource provided by biobanks. Here, a national digital pathology infrastructure has been established at Austrian medical universities employing latest scanning technology to generate a unique imaging data resource to drive machine learning and imaging biomarker development (Fig. 3). Developments in machine learning have created an extensive interest in large-scale imaging data of tissues that generate synergies between biobanks, digital pathology and information and communication technology (ICT) industry for driving innovation in imaging biomarkers.

\section{Future Challenges}

There is a need for large-scale and standardised annotation of training data sets and to make results generated by machine learning explicable. Developments in digital pathology and imaging are converging to create a stimulating momentum for innovation in $\mathrm{AI}$ and imaging biomarkers. The increasing role of accessing large data sets and the need for international collaboration including data 


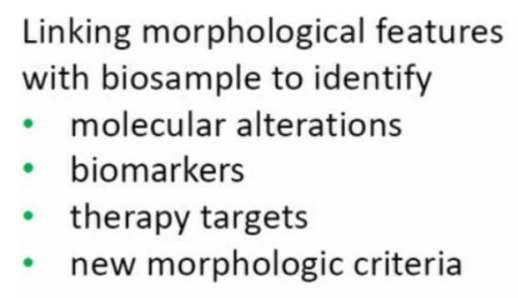

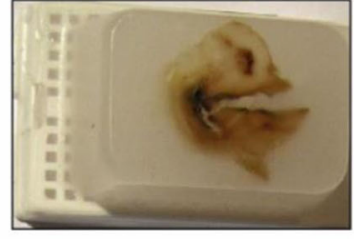

FFPE block
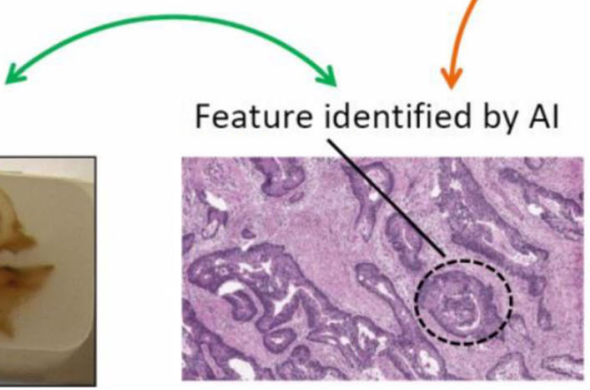

Digital slide
Linking morphological features

with disease outcome
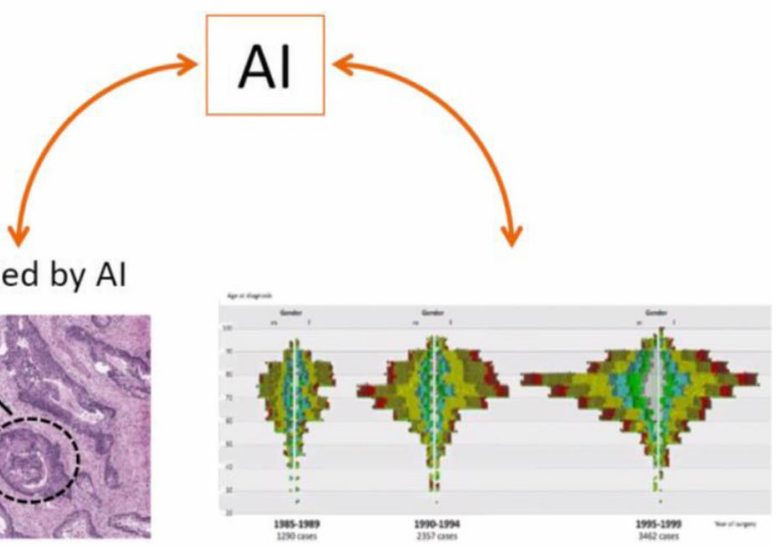

Disease outcome

Fig. 3. Biobanks and machine learning/artificial intelligence (Al): a novel way of linking biosamples, images and disease outcome.

exchange pose new challenges in privacy protection and ethical and legal compliance.

\section{Molecular Imaging and Omics}

\section{The Issues}

Recent large-scale trials that target exploitable mutations pharmacologically have yielded largely disappointing results. This can be explained in parts by the limited number of effective targeted drugs, the small number of cancers that exhibit single oncogene addictions and, thus, the susceptibility to single-drug treatments. Furthermore, targeting a comparatively large number of mutations requires rationally designed combination therapies. Thus, precision oncology based on genomics remains an elusive goal $[6,39]$.

\section{Recent Advances}

Theranostics is an example of precision medicine. It combines target identification and confirmation with therapies that bind to the same target with high affinity and specificity. Recent reports on targeting fibroblastactivated protein (FAP), a highly relevant tumour stroma target, suggest numerous potential theranostic applications across many cancers [40] (Fig. 4). Other examples for image-derived predictive biomarkers include assessments of hormone receptor status (estrogen receptors, androgen receptors) [41, 42], protein expression (human epidermal growth factor receptor 2 (HER2neu)) and many more [43].

\section{Future Challenges}

$\mathrm{n}$ light of the significant differences between the results of genomic testing obtained from tissue, liquid biopsies and molecular imaging, a consensus should be developed to integrate the results of these disparate yet complementary diagnostic modalities in a disease-specific manner [44]. This requires new methodological approaches towards the combination of multi-parametric image features (aka "radiomics") and multi-omics data from tissue or liquid biopsies so as to yield clinically relevant information. Here, artificial intelligence-based approaches have been proposed as one way to derive predictive biomarkers for therapeutic responses in cancer [45, 46].

\section{Digital Biomarkers and Patient Data Mining}

\section{The Issues}

Information technology (IT) and companies have transformed our digital footprints into an important commodity. Collections of heterogeneous data from a multitude of sources, such as social network posts and biosensors, are increasingly used for health-related predictions. The challenge presented by the unstructured, 
a

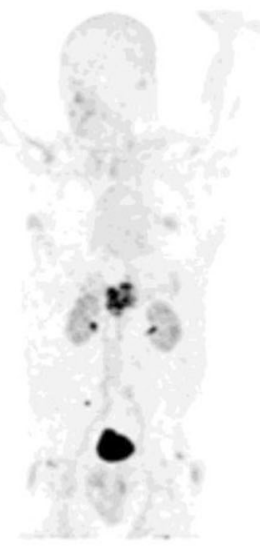

$1 \mathrm{~h}$

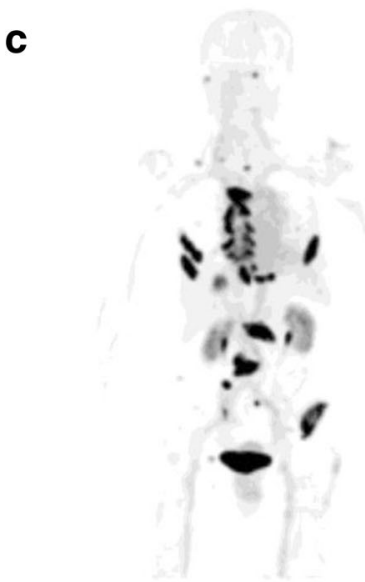

$10 \min$
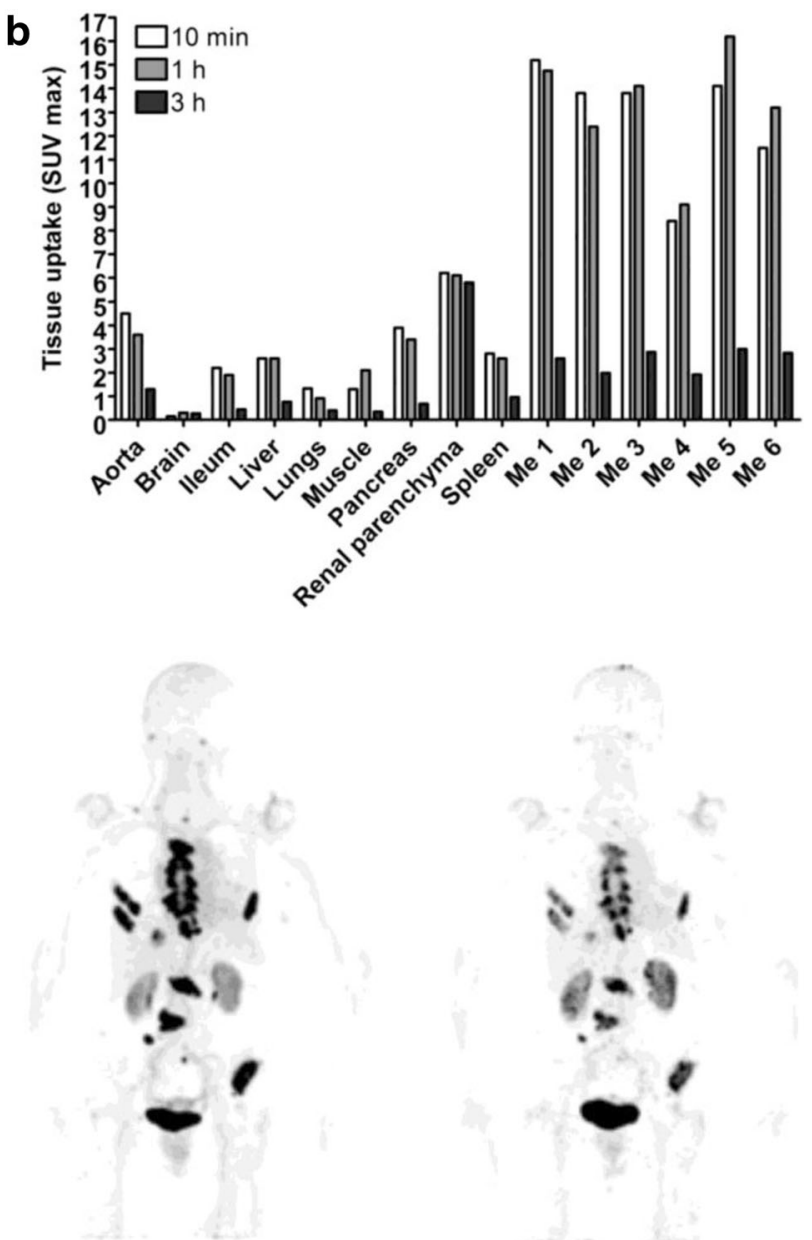

$1 \mathrm{~h}$

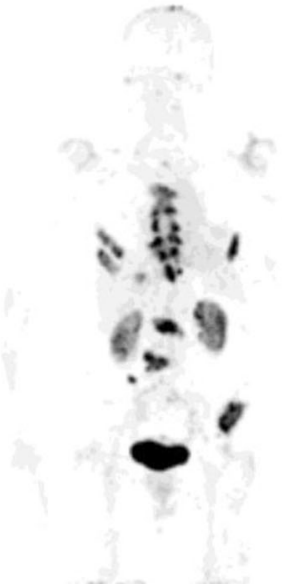

$3 \mathrm{~h}$

Fig. 4. PET/CT maximum-intensity projections of patient with metastasised pancreatic cancer (a) and patient with breast cancer (c). Maximum standardized uptake (SUVmax) of 68Ga-labelled FAPI in breast cancer lesions; Me = Metastasis. Note the favourable biodistribution of the FAPI ligand for use as a theranostic compound with very high target and very low background activity. Image taken from [40] with approval by publisher.

noisy and incomplete nature of these data is addressed by a new generation of powerful, neural network-based classification technologies (Fig. 5) [47].

\section{Recent Advances}

The term "digital biomarkers" was coined to denote objective, quantifiable physiological and behavioural data collected and measured by means of portable, wearable or implantable devices [48]. Digital biomarkers are data or data extracts that can be obtained from all kinds of artefacts related to an individual, and on which health-related predictions can be grounded. Digital biomarkers can be harvested from mobile appliances as well as raw textual and other signals, through publicly available sources and electronic health records (EHRs). Likewise, the potential of big data analytics for healthcare, including digital biomarkers, and prevention is well appreciated $[49,50]$.

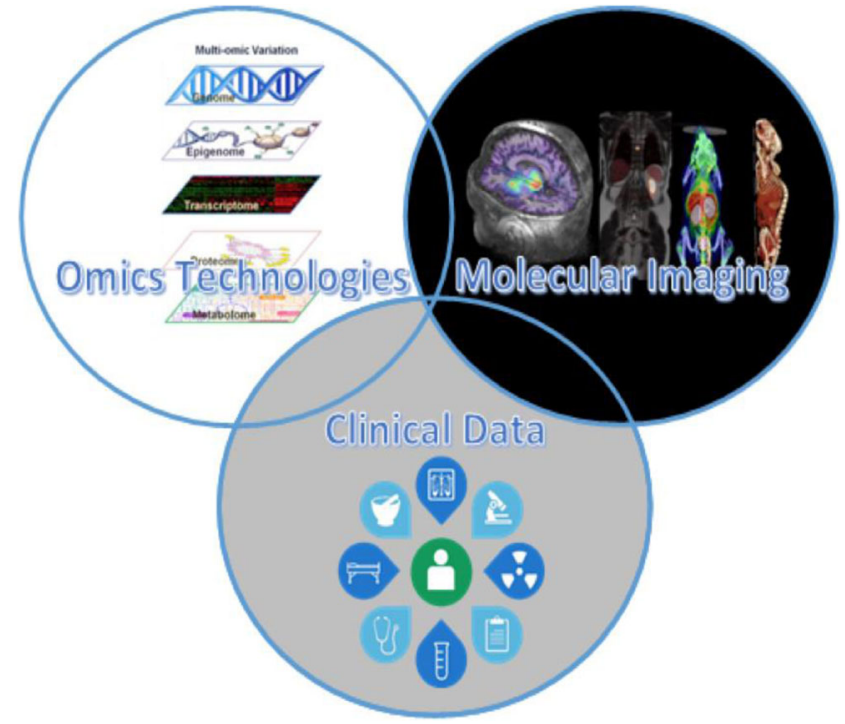

Fig. 5. The triangle between imaging, omics and networks and clinical data. 


\section{Future Challenges}

The application of digital biomarkers in clinical decision support systems requires a higher level of standardisation. By nature, data in electronic health records are heterogeneous, and are primarily collected for human communication and documentation, but not intended for automated decision support or risk stratification. Therefore, the digital footprint of EHR data is neither well-structured nor complete. Most of EHRs are plain text, and structured information is collected for purposes, such as billing, quality assurance and disease reporting only.

Adequate secondary use of EHR data, according to the FAIR (Findable, Accessible, Interoperable and Re-Usable) data principles [51], is a challenge for natural language processing (NLP) approaches [52], supported by domain terminologies and ontologies [53-55]. Due to different levels of complexity and missing contextual information, distinct strategies are required to transform existing EHR data for the use of data mining. Once the individual patient data is formatted and prepared, it will be necessary to validate these digital biomarkers in prospective study settings.

\section{Interactomics}

\section{The Issues}

Interactomics is a crossover discipline at the intersection of bioinformatics and molecular biology that relates to the studies of physical or functional interactions of proteins and other molecules within a cell and the consequences of those interactions. Networks provide a data-driven and simple but integrative mathematical framework for the inference of genotype-phenotype relationships that can handle large-scale molecular data, which reflect complex molecular relationships but may be governed by small quantitative differences and may carry methodological biases.

Being a critical component of the genotype-phenotypefunction paradigm, networks provide a framework that most directly connects molecular information such as sequence variants to phenotypic traits [56]. However, a gap exists between nucleotide resolution genome data and proteomics data, which typically refer to changes of a protein as a whole [57].

\section{Recent Advances}

The parallel quantification of proteomes from a series of cancer cells recently established a connection between copy number variation [58] or nucleotide variation [59] and proteome changes at the protein interaction network level. Concerted proteome changes can be linked to genetic changes via data integration with networks using interactome network models.
A second new development addressing the resolution gap between proteomics and genomics involves deep mutational scanning approaches [60]. Highly diverse genetic libraries, e.g., representing all single-amino acid substations of a protein of interest, are coupled to a phenotypic selection and can be assessed through massive parallel sequencing. Recently, a novel approach that couples deep scanning mutagenise to protein interaction networks via a reverse yeast two-hybrid technique was introduced [61].

\section{Future Challenges}

Today, amino acid resolution protein interaction profiles can be recorded on an interactome scale. Interaction perturbation profiles could potentially serve as a sequencebased functional biomarker with the advantage to include rare and newly diagnosed gene variants. Nonetheless, efforts must focus on human interactome mapping that also addresses condition- and tissue-specific network information. Here, computational methods will play a crucial role in transforming current data generation approaches into diagnostic or clinically applicable information.

\section{Track 2: Biomarker and Treatment}

Biomarkers can serve as surrogates for the presence of respective treatment-relevant target structures when selecting and guiding targeted therapies in cancer patients (Table 3). The derivation of biomarkers is considered as a costintensive process that helps generate very useful and costeffective databases for local and remote teams working in the field of drug discovery. Therefore, standardisation of biospecimen and biomarker sourcing procedures is a key to an efficient biomarker derivation and validation and subsequent data analysis [7].

\section{The Needs for Standardised Pre-analytics in Biobanking}

The Issues According to Freedman and Inglese, the share of pre-clinical, biological research studies that failed to be reproduced ranges from 68 to $89 \%$ [62]. It is estimated that in the USA alone, US\$28 billion is wasted annually due to irreproducible results, with over a third of it being caused by poor reference materials and biological reagents [63]. Thus, it is not surprising that more than half of the papers reporting

Table 3. Track 2: progress indicators for biomarkers and treatment planning

\begin{tabular}{lcc}
\hline Feature & 2016 & 2018 \\
\hline Biobanks and evidence creation & $\leftrightarrow$ & $\leftrightarrow$ \\
Standardisation of pre-analytics biobanks & $\leftrightarrow$ & $\leftrightarrow$ \\
GMP as roadblock to translational research & $\nearrow$ & $\nearrow$ \\
Tracers for the immune system & $\leftrightarrow$ & $\nearrow$ \\
Clinical immunotherapy & $\leftrightarrow$ & $\nearrow$ \\
\hline
\end{tabular}


biomarker discoveries do not contain any information about the biospecimens used, although some of them were published in interdisciplinary top journals [64].

Recent Advances To minimise pre-analytical variability in research biobanking, large biobank consortia, such as the European Research Infrastructure Consortium BBMRIERIC and its national nodes, foster the implementation of technical specifications (TSs) during the pre-examination phase [65]. Given that governance aspects, ethical requirements and sample access remain largely undervalued, an international biobank-specific quality management standard (ISO 20387- “General requirements for Biobanking") was recently released. TSs on the pre-examination process require the validation of the whole process, which starts with the collection of the sample and ends with the interpretation of the analytical results.

Future Challenges Despite increasing evidence of a higher pre-analytical quality positively affecting research reproducibility and scientific progress, the community must engage in building and adhering to evidence-based international protocols [66-68].

\section{Standardised Pre-analytics in Biomarker Research}

The Issues Profiles of biomolecules can change significantly during pre-analytical workflows. Previous studies have demonstrated that changes in RNA expression or protein and phosphoprotein amounts can occur at every stage of the sample processing workflow starting with the collection and extending to the archival of the processed samples [69-72]. This can lead to unreliable results or misinterpretation of the bioanalytical profiles generated in the pre-analytical phase. Of note, diagnostic errors contribute to up to $10 \%$ of all patient deaths and $17 \%$ of adverse events. The pre-analytical workflows are the largest contributors to the error rate and account for $46-68 \%$ of clinical laboratory errors [73].

Recent Advances A new EU In Vitro Diagnostic Device Regulation 2017/746 [74] (IVDR) was put into effect in May 2017, thereby replacing the old IVD Directive 98/79/ EC (Official Journal of the European Union, Legislation, Vol. 60, May 5, 2017). A key modification in the new IVDR is the introduction of sampling requirements for the analytical performance of an in vitro diagnostic test.

The new Horizon 2020 SPIDA4P consortium project (2017-2020) intends to broaden the portfolio of CEN and ISO standards for pre-analytical workflows by generating and implementing finally a comprehensive portfolio of 22 pan-European pre-analytical CEN/technical specifications and ISO/international standards, addressing important pre- analytical workflows such as those applied to personalised medicine (www.spidia.eu).

Future Challenges Additional new pre-analytical workflow technologies and IVD products on specimen and sample collection, stabilisation, transport, storage and processing are still required for various new applications, e.g., for CTC characterisation, circulating nucleic acid analysis from non-invasive human samples, next-generation sequencing (NGS) and metabolites in human samples. In addition to supporting technology advances, the implementation of the new IVDR and CEN and ISO standards for pre-analytical workflows will remain a major task for the next years. Corresponding external quality assurance (EQA) schemes will be developed and implemented as well, aiming to survey the resulting quality of samples and diagnostic practice.

\section{Role of Mass Spectrometry in Quality Analysis and Analytics}

The Issues In mass spectroscopy, determinants that may compromise sample quality must be minimised [75] in order to obtain samples that assure reproducible and credible results. Despite great efforts to reduce the error rates of preanalytical stage of sample handling, pre-analytical errors still account for up to $70 \%$ of all problems occurring in laboratory diagnostics [76-78] and include hemolysis, coagulation (clotting), inadequate filling volume of the blood collection vial and insufficient information on the blood collection rube or the sample vial [79-82].

Recent Advances For example, the quality of blood samples can be affected in multiple ways [83]. It was found that $4-19 \%$ of metabolites were upregulated by mishandling of the samples and 8-12\% of single metabolites were downregulated compared to control samples. Another study from the same group demonstrated significant changes of metabolites when the incubation time of blood samples was prolonged [81]. In particular, amino acids and nucleobases were demonstrated to be sensitive for these affections.

Future Challenges Ongoing studies accentuate the importance of high-quality biospecimens in the biobanks, as well as a need for identification of more biomarkers of sample quality.

\section{Translational Immunology: Tackling Barriers in Science and Bureaucracy}

The Issues Immunotherapy has become a mainstay of oncological treatment. The ability to stimulate Fc receptor (FcR)-bearing effector cells, which results in lysis of target cells (antibody-dependent cellular cytotoxicity (ADCC)), is 
central for the immunotherapeutic activity of monoclonal antitumour antibodies, in particular in hematological malignancies. In humans, natural killer (NK) cells constitute the major cell population that mediates this important antibody function [84]. However, the success of rituximab and other so far available antitumour antibodies is limited with regard to efficacy and due to the lack of compounds for many other cancer entities.

A major drawback of strategies to mobilise $\mathrm{T}$ cells against cancer is that they cause partially severe side effects. In case of checkpoint blocking antibodies, these arise from the general, undirected activation of the T cell system. In case of presently available bispecific antibodies (bsAbs) and chimeric antigen receptor (CAR) T cells, side effects are largely due to the fact that the employed target antigens are expressed not only on malignant but also on healthy cells, such as B cells in case of CD19. A second major drawback is, as mentioned above, that available bsAbs and CAR T cells are far less successful in solid tumours than hematopoietic malignancies.

Recent Advances Hofmann and collaborators [85] recently developed an $\mathrm{Fc}$-optimised monoclonal antibody targeting the surface antigen FLT3 (CD135), which is expressed on leukemic cells in nearly all patients with acute myeloid leukaemia (AML), for which no immunotherapy is available to date. An alternative approach to improve the therapeutic efficacy of antitumour antibodies is to develop strategies, which allow for antibody-mediated stimulation of $\mathrm{T}$ cells with their-compared to NK cells-profoundly higher effector potential [86].

A recent publication confirmed the relevance of targeting vascular antigens for cancer treatment [87]. Accordingly, a bsAb directed to prostate-specific membrane antigen (PSMA) was developed, which is expressed on prostate carcinoma cells as well as on tumour-associated vasculature of numerous other cancers. This PSMAxCD3 bsAb termed CC-1 was constructed in a novel, whole IgG-based (IgGsc) format with increased serum half-life. CC-1 contains a proprietary PSMA antibody, which displays additional unique reactivity with squamous cell carcinoma (SCC) of the lung, allowing for the desired dual targeting of both tumour cells and neovasculature.

Future Challenges A plethora of compounds with preclinically substantiated antitumour efficacy awaits clinical evaluation and holds great promise to benefit cancer patients. At present, the biggest challenge is the steadily increasing regulatory burden with regard to both requirements regarding production (good manufacturing practice, GMP) and lately also for clinical evaluation (good clinical practice, GCP). Together, they dramatically extend the time from conceptualisation of a drug to its clinical evaluation, but notably, the first also almost completely bars academic institutions from drug development [88]. It is worth to consider whether and how in the particular case of cancer patients with a life-threatening disease, who failed to respond to established/available therapy, novel compounds with pre-clinically proven efficacy can be made more rapidly available. In addition, the costs of drug development and ultimately treatment costs, which are becoming a tremendous socio-economic challenge in the future, must become a focus of our attention.

\section{Tracers to Target the Immune System}

The Issues Immune-modulating therapies not only target the cancer cells but also modulate the cancer-promoting or cancer-inhibiting properties of the complex multi-cellular tumour microenvironment (TME) [89-91]. There are still a large number of patients that do not respond to the chosen immune-modulating therapy. Therefore, understanding the dynamic changes in the TME, in particular those involving the immune system, may help advance the development of new strategies for cancer diagnosis, treatment and assessment of therapeutic response.

Thus, there is a need for translational and validated biomarkers for the prediction and monitoring of responders to immune system-modulating drugs and categorising responsive tumours early after therapy initiation in a noninvasive manner. Unfortunately, an increase of infiltrating immune cells that have an increased glucose metabolism compared with peripheral non-immune cells pretends a transient worsening (pseudo-progression) in $\left[{ }^{18} \mathrm{~F}\right] \mathrm{FDG}$ PET [92].

Recent Advances Currently, one of the most interesting targets for therapy and imaging is the immune checkpoint protein, PD-1 ligand (PD-L1). PD-L1 is over-expressed by a variety of tumour cells, induced as an adaptive mechanism in response to tumour-infiltrating cytotoxic $\mathrm{T}$ cells [93]. Increased PD-L1 expression in cancer cells as well as in TME promotes immune evasion of tumour cells via binding to PD-1 expressed by the active immune infiltrates [94]. A number of studies have demonstrated anticancer activity of PD-L1-targeting antibodies [95]. For in vivo detection of PD-L1, clinical advances have been made using radiolabelled antibodies such as atezolizumab (ClinicalTrials.gov identifiers NCT02453984 and NCT02478099) [96].

In addition, other key mediators in immune cell activation/inactivation and various types of cells involved in immune regulation offer additional potential targets for imaging response to immunotherapy [97]. Novel, potential targets and targeting agents are currently under investigation [98]. A list of immunotargets and targeting concepts is shown in Table 4.

Future Challenges Major challenges on the way to imaging biomarkers in immunotherapies include 
Table 4.. Targets and nuclear targeting concepts and agents that are currently under investigation for monitoring immunotherapies (adapted from [99] and expanded)

\begin{tabular}{|c|c|c|}
\hline Target & Cell type and function & Proposed tracers \\
\hline PD-L and PD-1 & $\begin{array}{l}\text { Tumour/tumour-immunosuppressive } \\
\text { microenvironment }\end{array}$ & $\begin{array}{l}{\left[{ }^{89} \mathrm{Zr}\right] /\left[{ }^{64} \mathrm{Cu}\right] \text { anti-PD-L1-Ab/peptide; }} \\
{\left[{ }^{89} \mathrm{Zr}\right] \mathrm{MPDL} 3280 \mathrm{~A} ;} \\
\\
{\left[{ }^{64} \mathrm{Cu}\right] 10 \mathrm{~F} \text {.9G2 }[96,100]}\end{array}$ \\
\hline Deoxycytidine kinase & Immune cell proliferation & $\mathrm{L}-\left[{ }^{18} \mathrm{~F}\right] \mathrm{FAC}[101,102]$ \\
\hline Deoxyguanosine kinase & T lymphocyte activation & {$\left[{ }^{18} \mathrm{~F}\right] \mathrm{AraG}[103]$} \\
\hline CD8 & Cytotoxic T lymphocytes & $\begin{array}{l}{\left[{ }^{89} \mathrm{Zr}\right] /\left[{ }^{64} \mathrm{Cu}\right] \text { anti-CD8-Ab; }} \\
\quad\left[{ }^{89} \mathrm{Zr}\right] \text { anti-CD8-cys diabody; } \\
\quad\left[{ }^{89} \mathrm{Zr}\right] \text { anti-CD8-minibody } \\
\quad\left(\left[{ }^{89} \mathrm{Zr}\right] \mathrm{IAB} 22 \mathrm{M} 2 \mathrm{C}\right)[104,105]\end{array}$ \\
\hline CTLA-4 & T lymphocyte inhibition & {$\left[{ }^{64} \mathrm{Cu}\right] \mathrm{anti}-\mathrm{CTLA}-4-\mathrm{Ab}[106]$} \\
\hline CD47 & $\begin{array}{l}\text { Tumour-associated macrophages } \\
\text { (TAMs) }\end{array}$ & {$\left[{ }^{89} \mathrm{Zr}\right]$ anti-CD47-Ab [107] } \\
\hline CD11b/MHC-II & Neutrophils & {$\left[{ }^{18} \mathrm{~F}\right] /\left[{ }^{64} \mathrm{Cu}\right]$ anti-CD11b/MHC-II-Ab [62] } \\
\hline $\begin{array}{l}\text { Transgenic T } \\
\text { cell receptor (TCR) }\end{array}$ & Transgenic $\mathrm{T}$ cells & {$\left[{ }^{89} \mathrm{Zr}\right] /\left[{ }^{64} \mathrm{Cu}\right]$ anti-TCR-Ab $[108,109]$} \\
\hline CXCR4 & T lymphocyte trafficking & {$\left[{ }^{68} \mathrm{Ga}\right]$ pentixafor $[110]$} \\
\hline $\begin{array}{l}\text { B7-1 (CD80) and } \\
\text { B7-2 (CD86) }\end{array}$ & $\begin{array}{l}\text { Activated antigen-presenting cells, } \\
\text { macrophages (TAMs) }\end{array}$ & {$\left[{ }^{111} \mathrm{In}\right] /\left[{ }^{64} \mathrm{Cu}\right]$ belatacept $[111]$} \\
\hline FR- $\beta$ & Macrophages (TAMs) & {$\left[{ }^{18} \mathrm{~F}\right] \mathrm{AzaFol}[112,113]$} \\
\hline
\end{tabular}

translational gaps as a result of lack of or inadequate in vitro and animal models that allow assessing novel radiotracers; the time for clinical validation of novel, imaginable biomarkers; repetitive exposure of patients to ionising radiation; and the cost for tracer development and clinical studies.

\section{Targeting the Immune System: a Clinical Perspective}

The Issues Tumour cells express or induce molecules, which block cytotoxic tumour ablative immune cells, such as cytotoxic T cells [114]. Vice versa, a rational and efficient tumour immunotherapy is based on the identification and subsequent blockage of those pathways by immune checkpoint inhibitors.

Recent Advances One of the best predictive markers for PD-1 blockade is microsatellite instability (MSI) [115]. It is anticipated that the MSI-associated increase in mutations resulting in an increased rate of neo-antigens is substantial for the observed therapeutic effect in those patients.

In 2017, the FDA approved PD-L1 inhibitors for unresectable or therapy-resistant metastatic MSI-positive solid cancer. An association of mutational burden and a therapeutic effect of a checkpoint blocker have also been demonstrated for the CTLA-4 antibody ipilimumab [116]. The PD-L1 inhibitor pembrolizumab revealed a benefit for patients with metastatic non-small cell lung cancer (NSCLC) compared to platinum-based chemotherapy with an overall response rate of $45 \%$ versus $28 \%$, respectively [117].

PD-L1 or PD-1 blockade have also been highly successful in phase II studies in Morbus Hodgkin, leading to an overall response rate of more than $60 \%$. In this disease, the expression of the receptors is increased due to genetic aberrations, such as copy gain or amplification [118]. Currently, the EMA approval of checkpoint inhibitor includes MSI cancer, NSCLC, Hodgkin lymphoma, melanoma, head and neck cancer, urothelial cancer, kidney cancer and Merkel cell cancer.

Future Challenges The success of these initial studies did not only promote the development of antibodies against other checkpoint molecules, such as LAG3 or TIM3, but also combination therapy with other agents. Despite first publications showing anti-PD-1 antibody to be effective also in microsatellite-stable cancers in light of combination therapies [99, 119], future studies have to provide additional evidence of such combined approaches.

Oncolytic viruses have been developed for most of the viral families [120], and the combination of an FDAapproved oncolytic herpes virus with an anti-PD-L1 antibody led to a clinical response of around $60 \%$ in stage III and stage IV melanoma. The effect was associated with a high influx of cytotoxic $\mathrm{T}$ cells and an increase of PD-1 expression in tumour tissue. However, proof of evidence is required to implement these approaches into the clinic.

\section{Track 3: Evidence and Ethics}

Until recently, drug development followed a clear path, i.e., from in vitro pharmacodynamic studies and experiments in animals to first-in-men studies in healthy volunteers as well as in patients. If successful, this process would be followed by approval through regulators and, finally, reimbursement negotiations with payers. While this one-way pathway employing the interaction between stakeholders at predefined time points clearly still does exist, recent 
approaches aim at early and more flexible interactions of involved players.

Medical ethics does play a key role during these stages (Table 5), perhaps best defined in the sixth paragraph of the Declaration of Helsinki, the key document for ethics in medical research: "The primary purpose of medical research involving human subjects is to understand the causes, development and effects of diseases and improve preventive, diagnostic and therapeutic interventions (methods, procedures and treatments). Even the best proven interventions must be evaluated continually through research for their safety, effectiveness, efficiency, accessibility and quality." (https://www.wma.net/policies-post/wma-declaration-of-helsinki-ethical-principles-for-medical-research-involving-human-subjects/). This depicts well the inseparable binding between ethics ("what can I do?") and evidence ("what do I know?" and "what do I want to know?") but also encourages the community as such to continuously challenge their "standard of care".

\section{Cost-Effectiveness Aspects of Biomarker Development}

The Issues Providing value for money, identifying the best course of action based on the available evidence and optimal allocation of resources from the given budget are the central concepts of cost-effectiveness analyses (CEAs). CEAs evaluate the difference in costs relative to the difference in effects between competing alternative activities. They are commonly used decision-making support tools in the context of health economics and health technology assessments (HTAs) to identify the value of new health technologies.

The top ten most common medications in the USA help between 4 and $25 \%$ of patients [121]. Spending on cancer drugs has increased faster than spending in most other areas of healthcare, because of rising prices and increased use. Diminishing rate of return in terms of the benefit gain associated with the increased costs is another concern [122].

Recent Advances Biomarkers may present multi-faceted values: clinical value is achieved by directing effective targeted therapy, informative value is achieved by reduced uncertainty about treatment benefits, financial value is achieved by reducing costs spent on ineffective care and economic value is achieved by providing greater benefits for the amount paid than the benefits of potential alternative use of the same resources (the so-called "opportunity cost") [123].

Traditional HTAs and CEAs focus on population average results to support population-level reimbursement decisions and generally ignore patient variations or broader value aspects leading to potentially ineffective and futile use of healthcare resources. Establishing the different value aspects of biomarker tests requires the application of a broader value framework and the explicit consideration of patient heterogeneity [124].

Future Challenges Conducting the value evaluation of biomarker tests usually require more data, time and analytical resources than traditional pharmacoeconomic evaluations. Although procedurally challenging, early inclusion of HTA in the development process can promote costeffectiveness of the developed test. Since relevant evidence may not be available at the time of readiness for marketing, new reimbursement policy models (e.g., cloverage with evidence development) are also required to allow the earliest possible availability for patient care [125].

\section{Precision Medicine: Mapping the Ethical Challenges}

The Issues One of the central technical challenges of any biomarker-focused precision medicine approach is successful translation from bench to bedside and from lab to lifeworld [126]. On the technical side, and as evidenced at the meeting, significant work is currently being done to ensure advanced biomarkers are developed that are clinically actionable and help improve understanding of disease progression and individual patient care. However, to reach this goal, technology and clinical development need to consider various important ethical and social issues.

Recent Advances A knowledge gap with doctors regarding the multiplexed facets of biomarker development and use has been identified [127]. However, studies on how this gap plays out in clinical decision-making and how it can be managed or even avoided are missing. Likewise, more information on patients' understanding of advanced biomarker approaches, their expectations, attitudes and values as well as their concerns need to be collected, to assist future patient care and policymaking. From a philosophical perspective, understandings and illness taxonomies are

Table 5. Track 3: progress indicators for ethics and evidence aspects of biomarker development

\begin{tabular}{lccc}
\hline Feature & 2016 & 2018 \\
\hline Biomarker as a decision tool for regulators like EMA and FDA & $\leftrightarrow$ & & \\
Biomarker considered by payers & $\leftrightarrow$ & $\nearrow$ \\
Biomarker reflected in scientific guidelines & $\nearrow$ & $\hookrightarrow$ \\
Biomarker impact on ethics committee approval & $\nearrow$ & $\hookrightarrow$ \\
Addressing ethical issues in personalised medicine & $\leftrightarrow$ & $\leftrightarrow$ \\
\hline
\end{tabular}


currently shifting [128]. On the sociological side, important discussions focus on whether precision medicine contributes to the medicalisation of pre-disease states and/or social trends, and whether precision medicine could potentially be a poor choice while a low-tech public health approach is perhaps more appropriate and cost-effective.

Future Challenges Studies mapping the specific ethical and social issues of advanced biomarker approaches, including the studied disease entities, are required.

\section{Value of Diagnostics to Health Systems}

The Issues Research and development need to be mindful of the ultimate aim of healthcare technologies. The last hurdle for these technologies to access the market is reimbursement. Such decisions are often preceded by an HTA, which is mandatory in many countries for pharmaceuticals and is increasingly being undertaken for medical devices and other diagnostic technologies and activities in Europe.

Recent Advances Clinical value is measured in population health, often using generic metrics that allow cross-condition comparisons. In the UK and many other European countries, the measure used is the quality-adjusted life year (QALY). Because any additional costs imposed on the healthcare system means that these resources cannot be used in other ways, some health is lost or foregone (aka "health opportunity costs").

With regard to diagnostic tests, HTA often considers not only which test should be used in clinical practice but also how the test should be used, that is, what is the best way to proceed, clinically, using the information it provides [124, 129-132].

Future Challenges The mechanism of value accrual for diagnostic technologies differs to that of pharmaceuticals. Tests identify the level or magnitude of factors that determine or explain health outcomes. In this regard, tests identify patients who are expected to benefit most from distinct regimens of healthcare. It is only by tailoring treatment decisions to patients, that is the expected (net) health of the overall population improves and value is generated. This means that, ultimately, the value of the test is bound by the value of available treatments and conditioned by other technologies in the diagnostic pathway (e.g., combinations of tests or sequences of tests). Value also critically depends on prevalence, on the costs or adverse events of the technology and on the level of misclassification (false positives and false negatives).

\section{Paradigm of Predictive Medicine and Ethical Challenges}

The Issues The possible role of genetic information in a future healthcare system, in which "systems medicine" approaches (Fig. 6) are applied, is currently intensely debated [133-136]. But, the question of whether the importance and role of genetics will either increase or decrease in such a healthcare system remains unanswered.

Recent Advances Systems medicine reconciles heterogeneous approaches, using not only modelling methods of systems biology to obtain information about the aetiology of complex diseases but also integrating big amounts of data from various sources (omics data, data from imaging methods, treatment data, etc.) as well [137-140]. By committing itself to the paradigm of predictive medicine, ethical challenges remain highly virulent in the approach of systems medicine. Depending on a specific disease, systems medicine could contribute to a boost of genetic prediction and could strengthen the role of non-genetic predictors [133, $139,141,142]$.

Future Challenges The question of how patients and doctors can deal with probabilities and risks must be addressed and communicated across all stakeholders. Here, the question of a future relevance of algorithms and scores for the decision-making process within the context of a medical treatment is crucial. The problem of so-called "health-related personal responsibility" remains potentially as relevant for systems medicine as it is for the approaches of precision medicine and individualised medicine. Challenges regarding the clinical processing of incidental or secondary findings could arise from the translation of systems medicine into clinical practice [138].

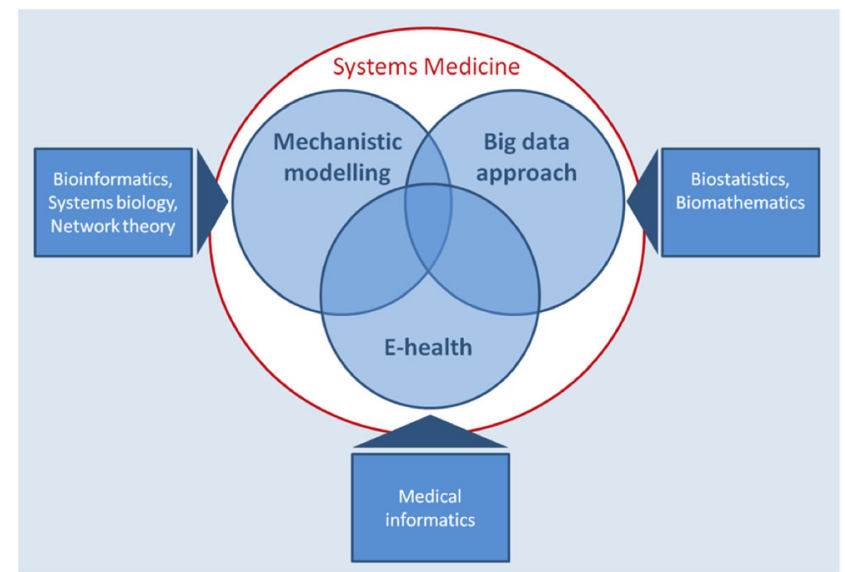

Fig. 6. Systems medicine can be understood as a heterogeneous set of methods and approaches connected by an emphasis on information technologies. 


\section{Round Table Discussion: What Is Needed to Breed the Next Generation of Experts in Molecular Diagnostics?}

It is obvious that current educational and training schemes that support the in-depth expertise of individual and autonomous fields of research are no longer appropriate to embrace the multi-disciplinary approach to (cancer) patient management [143]. This was obvious from a spirited debate as well. The panelists together with the audience then carved out requirements for the education of the next generation of biomarker experts, or "experts in molecular diagnostics".

In view of the existing gap between clinical and basic research expertise, which is a major bottleneck to generate experts in molecular diagnostics, it was reiterated that here are currently too few combined training pathways that provide training in genetics, inherited genetic disorders, oncology and molecular imaging. Moreover, limiting the preclinical competence to genomics ignores the critically important role of signaling networks in cancer and other diseases. Efforts should be made to introduce clinicians to animal models, drug development and biology of disease (in addition to imaging). Such improved mechanistic insights could lead to accelerated translation into clinical benefits. There is a need for compact training curricula as economic pressure including large debt volumes force trainees to join the work force quickly. It was suggested that there was an inverse relationship between general and speciality training. The sophistication and depth of knowledge and skills to practice molecular diagnostics would require 3-4 years of training and less general training. An alternative approach would be the expansion of postgraduate fellowships for physicians in molecular diagnostics. This should be synchronised with passion and enthusiasm among the faculty in order to most effectively spread the energy and excitement about molecular methodologies to trainees and colleagues.

Panelists and attendees appreciated the significant differences in career development opportunities between the USA and Europe (e.g., the nuclear medicine training duration is 5 years in Europe $v s .3$ years in the USA). Nonetheless, research fellowship like opportunities is available in both continents that could be used to strengthen the basic science component. The audience did not quite agree on whether creating more structured learning opportunities would enhance physicians' interest in pursuing research. However, it was conceded that clinicians were often poorly educated and informed about omics platforms, such as proteomics and metabolomics, and that such opportunities should be supported and sponsored by academic institutions, foundations and government agencies.

\section{Conclusions and Outlook}

Biomarker discovery and validation should become part of a "big science approach" [7], which involves multiple stakeholders from both academia and industry and experts in molecular pathology, genetics, molecular imaging, computer science, statistics, epidemiology, regulations and healthcare economics. However, such an approach mandates to overcome obstacles that reside within the existing culture of research organisations and ecosystems. Likewise, opportunities and abilities to communicate across stakeholders must be expanded, and deficiencies in (large sample) analytical technologies must be addressed.

The 2nd Donau Symposium provided an important forum for individuals involved in biomarker research with an empathy for cross-speciality engagement, such as in the validation of liquid biopsies and circulating tumour cells, where traditional single-feature biomarkers will be replaced by next-generation biomarker (e.g., derived from computational models). Cross-speciality engagement will yield also attention to the role of quantitative biomarkers, which is expected to grow [2]. When combining quantitative, visual and non-imaging biomarkers, standardised sourcing procedures as well as harmonisation measures will become essential for merging relevant information and building models and prediction algorithms that help advance patient management strategies.

In the future, the concept of precision medicine can be supported only if traditional ways of sourcing biomarker information are combined with environmental/lifestyle factors [144] and modern concepts of molecular imaging. While the 1st Donau Symposium in 2016 intended to blend, the 2nd in 2018 aimed to converge. We are now looking forward to our 3rd Symposium in 2020 to making it real!

Acknowledgments. Open access funding provided by Medical University of Vienna. We wish to thank all participants for their active contribution at the 2nd Donau Symposium and for the lively discussions. In particular, we like to acknowledge contributions from Claudia A. Castro Jaramillo, Stefanie D. Krämer and all faculty/moderators who did not engage in this white paper. Further, we like to acknowledge the generous support of the symposium sponsors: ABX advanced biochemical compounds, Austrian Institute of Technology (AIT) GmbH, BSM Diagnostica, DSD Pharma GmbH, Elimpex-Medizintechnik GmbH, Elysia-Raytest, Eurisotop, GE Austria, Hermes Medical Solutions, HVD Life Science Vertriebs GmbH, Iason $\mathrm{GmbH}$, Ipsen Pharma GmbH, ITM Isotopen Technologien München AG, Mediso GmbH, Philips Austria GmbH, Philogen, Qiagen, Rotem GmbH, Rotop, Seibersdorf Labor GmbH, Siemens Healthcare Diagnostics GmbH, Sofie Biosciences Acquired Zevacor and THP Medical Products Vertriebs $\mathrm{GmbH}$.

Funding Information. The SPIDIA project has received funding under the Seventh Research Framework Programme of the European Union, FP7HEALTH-2007-1.2.5, under grant agreement no. 222916. The SPIDIA4P project receives funding from the European Union's Horizon 2020 research and innovation programme under grant agreement no. 733112.

\section{Compliance with Ethical Standards}

\section{Conflict of Interest}

RJH holds stock in Telix Pharmaceuticals on behalf of the Peter MacCallum Cancer Centre.

$\mathrm{TB}$ is a co-founder of cmi-experts $\mathrm{GmbH}$. TB and $\mathrm{MH}$ are co-founders of Dedicaid GmbH. 
Open Access This article is distributed under the terms of the Creative Commons Attribution 4.0 International License (http:// creativecommons.org/licenses/by/4.0/), which permits unrestricted use, distribution, and reproduction in any medium, provided you give appropriate credit to the original author(s) and the source, provide a link to the Creative Commons license, and indicate if changes were made.

\section{References}

1. Ballman KV (2015) Biomarker: predictive or prognostic? J Clin Oncol 33:3968-3971

2. Lammertsma AA (2017) Forward to the past: the case for quantitative PET imaging. J Nucl Med 58(7):1019-1024

3. Bailey DL (2014) Thirty years from now: future physics contributions in nuclear medicine. EJNMMI Physics 1:4

4. Cancer Genome Atlas Research Network, Weinstein JN, Collisson EA, Mills GB et al (2013) The Cancer Genome Atlas Pan-Cancer analysis project. Nat Genet 45:1113-1120

5. Hacker M, Hoermann G, Kenner L (2018) Molecular imaging and molecular diagnostics: two sides of the same coin? Eur J Nucl Med Mol Imaging 45:1645-1648

6. Lee JK, Liu Z, Sa JK, Shin S, Wang J, Bordyuh M, Cho HJ, Elliott O, Chu T, Choi SW, Rosenbloom DIS, Lee IH, Shin YJ, Kang HJ, Kim D, Kim SY, Sim MH, Kim J, Lee T, Seo YJ, Shin H, Lee M, Kim SH, Kwon YJ, Oh JW, Song M, Kim M, Kong DS, Choi JW, Seol HJ, Lee JI, Kim ST, Park JO, Kim KM, Song SY, Lee JW, Kim HC, Lee JE, Choi MG, Seo SW, Shim YM, Zo JI, Jeong BC, Yoon Y, Ryu GH, Kim NKD, Bae JS, Park WY, Lee J, Verhaak RGW, Iavarone A, Lee J, Rabadan R, Nam DH (2018) Pharmacogenomic landscape of patient-derived tumor cells informs precision oncology therapy. Nat Genet 50:1399-1411

7. Poste G (2011) Bring on the biomarkers. Nature 469:156-157

8. Navin N, Kendall J, Troge J, Andrews P, Rodgers L, McIndoo J, Cook K, Stepansky A, Levy D, Esposito D, Muthuswamy L, Krasnitz A, McCombie WR, Hicks J, Wigler M (2011) Tumour evolution inferred by single-cell sequencing. Nature 472:90-94

9. Cleary AS, Leonard TL, Gestl SA, Gunther EJ (2014) Tumour cell heterogeneity maintained by cooperating subclones in Wnt-driven mammary cancers. Nature 508:113-117

10. Marusyk A, Tabassum DP, Altrock PM, Almendro V, Michor F, Polyak K (2014) Non-cell-autonomous driving of tumour growth supports sub-clonal heterogeneity. Nature 514:54-58

11. Koren S, Bentires-Alj M (2015) Breast tumor heterogeneity: source of fitness, hurdle for therapy. Mol Cell 60:537-546

12. Alix-Panabières C, Pantel K (2016) Clinical applications of circulating tumor cells and circulating tumor DNA as liquid biopsy. Cancer Discov 6:479-491

13. Babayan A, Pantel K (2018) Advances in liquid biopsy approaches for early detection and monitoring of cancer. Genome Med 10:21

14. Pantel K, Alix-Panabières $C$ (2010) Circulating tumour cells in cancer patients: challenges and perspectives. Trends Mol Med 16:398-406

15. Cohen JD, Li L, Wang Y, Thoburn C, Afsari B, Danilova L, Douville C, Javed AA, Wong F, Mattox A, Hruban RH, Wolfgang CL, Goggins MG, Dal Molin M, Wang TL, Roden R, Klein AP, Ptak J, Dobbyn L, Schaefer J, Silliman N, Popoli M, Vogelstein JT, Browne JD, Schoen RE, Brand RE, Tie J, Gibbs P, Wong HL, Mansfield AS, Jen J, Hanash SM, Falconi M, Allen PJ, Zhou S, Bettegowda C, Diaz LA Jr, Tomasetti C, Kinzler KW, Vogelstein B, Lennon AM, Papadopoulos N (2018) Detection and localization of surgically resectable cancers with a multi-analyte blood test. Science 359:926-930

16. Heitzer E, Haque IS, Roberts CE et al (2019) Current and future perspectives of liquid biopsies in genomics-driven oncology. Nat Rev Genet 20:71-88

17. Cristofanilli M, Hayes DF, Budd GT, Ellis MJ, Stopeck A, Reuben JM, Doyle GV, Matera J, Allard WJ, Miller MC, Fritsche HA, Hortobagyi GN, Terstappen LWMM (2005) Circulating tumor cells: a novel prognostic factor for newly diagnosed metastatic breast cancer. J Clin Oncol 23:1420-1430

18. Cohen SJ, Punt CJ, Iannotti N et al (2008) Relationship of circulating tumor cells to tumor response, progression-free survival, and overall survival in patients with metastatic colorectal cancer. J Clin Oncol 26:3213-3221

19. de Bono JS, Scher HI, Montgomery RB, Parker C, Miller MC, Tissing H, Doyle GV, Terstappen LWWM, Pienta KJ, Raghavan D (2008)
Circulating tumor cells predict survival benefit from treatment in metastatic castration-resistant prostate cancer. Clin Cancer Res 14:6302-6309

20. Riethdorf S, Müller V, Loibl S, Nekljudova V, Weber K, Huober J, Fehm T, Schrader I, Hilfrich J, Holms F, Tesch H, Schem C, von Minckwitz G, Untch M, Pantel K (2017) Prognostic impact of circulating tumor cells for breast cancer patients treated in the neoadjuvant "Geparquattro" trial. Clin Cancer Res 23:5384-5393

21. Siravegna G, Mussolin B, Buscarino M, Corti G, Cassingena A, Crisafulli G, Ponzetti A, Cremolini C, Amatu A, Lauricella C, Lamba S, Hobor S, Avallone A, Valtorta E, Rospo G, Medico E, Motta V, Antoniotti C, Tatangelo F, Bellosillo B, Veronese S, Budillon A, Montagut C, Racca P, Marsoni S, Falcone A, Corcoran RB, di Nicolantonio F, Loupakis F, Siena S, Sartore-Bianchi A, Bardelli A (2015) Clonal evolution and resistance to EGFR blockade in the blood of colorectal cancer patients. Nat Med 21:827

22. Tie J, Wang Y, Tomasetti C, Li L et al (2016) Circulating tumor DNA analysis detects minimal residual disease and predicts recurrence in patients with stage II colon cancer. Sci Transl Med 8:346ra92

23. Abbosh C, Birkbak NJ, Wilson GA et al (2017) Phylogenetic ctDNA analysis depicts early-stage lung cancer evolution. Nature 545:446451

24. Goodall J, Mateo J, Yuan W, Mossop H, Porta N, Miranda S, PerezLopez R, Dolling D, Robinson DR, Sandhu S, Fowler G, Ebbs B, Flohr P, Seed G, Rodrigues DN, Boysen G, Bertan C, Atkin M, Clarke M, Crespo M, Figueiredo I, Riisnaes R, Sumanasuriya S, Rescigno P, Zafeiriou Z, Sharp A, Tunariu N, Bianchini D, Gillman A, Lord CJ, Hall E, Chinnaiyan AM, Carreira S, de Bono JS, TOPARP-A investigators (2017) Circulating cell-free DNA to guide prostate cancer treatment with PARP inhibition. Cancer Discov 7:1006-1017

25. Stückrath I, Rack B, Janni W, Jäger B, Pantel K, Schwarzenbach H (2015) Aberrant plasma levels of circulating miR-16, miR-107, miR130a and miR-146a are associated with lymph node metastasis and receptor status of breast cancer patients. Oncotarget 6:13387-13401

26. Meng X, Müller V, Milde-Langosch K et al (2016) Circulating cellfree miR-373, miR-200a, miR-200b and miR-200c in patients with epithelial ovarian cancer. Adv Exp Med Biol 924:3-8

27. Al-Qatati A, Akrong C, Stevic I et al (2017) Plasma microRNA signature is associated with risk stratification in prostate cancer patients. Int J Cancer 141:1231-1239

28. Anfossi S, Babayan A, Pantel K, Calin GA (2018) Clinical utility of circulating non-coding RNAs - an update. Nat Rev Clin Oncol 15:541-563

29. Krimmel JD, Schmitt MW, Harrell MI, Agnew KJ, Kennedy SR, Emond MJ, Loeb LA, Swisher EM, Risques RA (2016) Ultra-deep sequencing detects ovarian cancer cells in peritoneal fluid and reveals somatic TP53 mutations in noncancerous tissues. Proc Natl Acad Sci U S A 113:6005-6010

30. Bardelli A, Pantel K (2017) Liquid biopsies, what we do not know (yet). Cancer Cell 31:172-179

31. Bednarz-Knoll N, Alix-Panabières C, Pantel K (2012) Plasticity of disseminating cancer cells in patients with epithelial malignancies. Cancer Metastasis Rev 31:673-687

32. de Leng WW, Gadellaa-van Hooijdonk CG, Barendregt-Smouter FA et al (2016) Targeted next generation sequencing as a reliable diagnostic assay for the detection of somatic mutations in tumours using minimal DNA amounts from formalin fixed paraffin embedded material. PLoS One 11:e0149405

33. Allen CE, Laetsch TW, Mody R, Irwin MS, Lim MS, Adamson PC, Seibel NL, Parsons DW, Cho YJ, Janeway K, on behalf of the Pediatric MATCH Target and Agent Prioritization Committee (2017) Target and agent prioritization for the Children's Oncology GroupNational Cancer Institute Pediatric MATCH Trial. J Natl Cancer Inst 109. https://doi.org/10.1093/jnci/djw274

34. Beyer T, Townsend DW, Brun T, Kinahan PE, Charron M, Roddy R, Jerin J, Young J, Byars L, Nutt R (2000) A combined PET/CT scanner for clinical oncology. J Nucl Med 41:1369-1379

35. Mannheim JG, Schmid AM, Schwenck J, Katiyar P, Herfert K, Pichler BJ, Disselhorst JA (2018) PET/MRI hybrid systems. Semin Nucl Med 48:332-347

36. Bailey DL, Pichler BJ, Guckel B et al (2018) Combined PET/MRI: global warming - summary report of the 6th international workshop on PET/MRI, March 27-29, 2017, Tubingen, Germany. Mol Imaging Biol 20:4-20 
37. Bailey DL, Pichler BJ, Guckel B et al (2016) Combined PET/MRI: from status quo to status go. Summary report of the fifth international workshop on PET/MR imaging; February 15-19, 2016; Tubingen, Germany. Mol Imaging Biol 18:637-650

38. Schwenck J, Rempp H, Reischl G, Kruck S, Stenzl A, Nikolaou $\mathrm{K}$, Pfannenberg C, la Fougère C (2017) Comparison of ${ }^{68} \mathrm{Ga}$ labelled PSMA-11 and ${ }^{11} \mathrm{C}$-choline in the detection of prostate cancer metastases by PET/CT. Eur J Nucl Med Mol Imaging 44:92-101

39. Snijder B, Vladimer GI, Krall N, Miura K, Schmolke AS, Kornauth C, Lopez de la Fuente O, Choi HS, van der Kouwe E, Gültekin S, Kazianka L, Bigenzahn JW, Hoermann G, Prutsch N, Merkel O, Ringler A, Sabler M, Jeryczynski G, Mayerhoefer ME, Simonitsch-Klupp I, Ocko K, Felberbauer F, Müllauer L, Prager GW, Korkmaz B, Kenner L, Sperr WR, Kralovics R, Gisslinger H, Valent P, Kubicek S, Jäger U, Staber PB, SupertiFurga G (2017) Image-based ex-vivo drug screening for patients with aggressive haematological malignancies: interim results from a single-arm, open-label, pilot study. Lancet Haematol 4:e595e606

40. Loktev A, Lindner T, Mier W, Debus J, Altmann A, Jäger D, Giesel F, Kratochwil C, Barthe P, Roumestand C, Haberkorn U (2018) A tumor-imaging method targeting cancer-associated fibroblasts. J Nucl Med 59:1423-1429

41. Schuster DM, Nanni C, Fanti S (2016) PET tracers beyond FDG in prostate cancer. Semin Nucl Med 46:507-521

42. van Kruchten M, de Vries EGE, Brown M, de Vries EFJ, Glaudemans AWJM, Dierckx RAJO, Schröder CP, Hospers GAP (2013) PET imaging of oestrogen receptors in patients with breast cancer. Lancet Oncol 14:e465-e475

43. Gaykema SB, Schröder CP, Vitfell-Rasmussen J et al (2014) 89Zrtrastuzumab and $89 \mathrm{Zr}$-bevacizumab PET to evaluate the effect of the HSP90 inhibitor NVP-AUY922 in metastatic breast cancer patients. Clin Cancer Res 20:3945-3954

44. Aggarwal C, Thompson JC, Black TA, Katz SI, Fan R, Yee SS, Chien AL, Evans TL, Bauml JM, Alley EW, Ciunci CA, Berman AT, Cohen RB, Lieberman DB, Majmundar KS, Savitch SL, Morrissette JJD, Hwang WT, Elenitoba-Johnson KSJ, Langer CJ, Carpenter EL (2018) Clinical implications of plasma-based genotyping with the delivery of personalized therapy in metastatic non-small cell lung cancer. JAMA Oncol 5:173. https://doi.org/10.1001/jamaoncol.2018.4305

45. Schmitz J, Schwab J, Schwenck J, Chen Q, Quintanilla-Martinez L, Hahn M, Wietek B, Schwenzer N, Staebler A, Kohlhofer U, Aina OH, Hubbard NE, Reischl G, Borowsky AD, Brucker S, Nikolaou K, la Fougère C, Cardiff RD, Pichler BJ, Schmid AM (2016) Decoding intratumoral heterogeneity of breast cancer by multiparametric in vivo imaging: a translational study. Cancer Res 76:5512-5522

46. Katiyar P, Divine MR, Kohlhofer U, Quintanilla-Martinez L, Schölkopf B, Pichler BJ, Disselhorst JA (2017) Spectral clustering predicts tumor tissue heterogeneity using dynamic ${ }^{18} \mathrm{~F}$-FDG PET: a complement to the standard compartmental modeling approach. J Nucl Med 58:651-657

47. Purwar A, Singh SK (2015) Hybrid prediction model with missing value imputation for medical data. Expert Syst Appl 42:5621-5631

48. Dorsey ER (2018) Digital biomarkers. https://www.karger.com/Journal/Home/271954. Journal, last accessed May 27, 2018

49. Sun J, Reddy CK $(2013$, 2013) Big data analytics for healthcare. Tutorial. Proc. of the 19th ACM SIGKDD international conference on Knowledge discovery and data mining. ACM:1525-1525 Slides: https://de.slideshare.net/ChandanReddy4/big-data-analytics-forhealthcare. Accessed 17 April 2019

50. Constine J (2017) Facebook rolls out AI to detect suicidal posts before they're reported. techcrunch.com 2017. https://techcrunch.com/2017/ 11/27/facebook-ai-suicide-prevention/. Accessed 17 April 2019

51. Wilkinson MD, Dumontier M, Aalbersberg IJ et al (2016) The FAIR guiding principles for scientific data management and stewardship. Sci Data 3:160018

52. Gonzalez-Hernandez G, Sarker A, O'Connor K et al (2017) Capturing the patient's perspective: a review of advances in natural language processing of health-related text. Year Med Inform 26:214-227

53. Freitas F, Schulz S, Moraes E (2009) Survey of current terminologies and ontologies in biology and medicine. RECIIS-Electronic J Comm Inform Innov Health 3:7-18
54. Schulz S, Jansen L (2013) Formal ontologies in biomedical knowledge representation. Yearb Med Inform 8:132-146

55. Zeng QT, Goryachev S, Weiss S, Sordo M, Murphy SN, Lazarus R (2006) Extracting principal diagnosis, co-morbidity and smoking status for asthma research: evaluation of a natural language processing system. BMC Med Inform Decis Mak 6:30

56. Stelzl U (2013) Molecular interaction networks in the analyses of sequence variation and proteomics data. Proteomics Clin Appl $7: 727-732$

57. Woodsmith J, Stelzl U (2017) Understanding disease variants through the lens of protein interactions. Cell Syst 5:544-546

58. Gonçalves E, Fragoulis A, Garcia-Alonso L, Cramer T, SaezRodriguez J, Beltrao P (2017) Widespread post-transcriptional attenuation of genomic copy-number variation in cancer. Cell Syst 5:386-398

59. Roumeliotis TI, Williams SP, Gonçalves E, Alsinet C, del Castillo Velasco-Herrera M, Aben N, Ghavidel FZ, Michaut M, Schubert M, Price S, Wright JC, Yu L, Yang M, Dienstmann R, Guinney J, Beltrao P, Brazma A, Pardo M, Stegle O, Adams DJ, Wessels L, SaezRodriguez J, McDermott U, Choudhary JS (2017) Genomic determinants of protein abundance variation in colorectal cancer cells. Cell Rep 20:2201-2214

60. Shendure J, Fields S (2016) Massively parallel genetics. Genetics 203:617-619

61. Woodsmith J, Apelt L, Casado-Medrano V, Özkan Z, Timmermann B, Stelzl U (2017) Protein interaction perturbation profiling at aminoacid resolution. Nat Methods 14:1213-1221

62. Freedman LP, Inglese J (2014) The increasing urgency for standards in basic biologic research. Cancer Res 74:4024-4029

63. Freedman LP, Cockburn IM, Simcoe TS (2015) The economics of reproducibility in preclinical research. PLoS Biol 13:e1002165

64. Simeon-Dubach D, Perren A (2011) Better provenance for biobank samples. Nature 475:454-455

65. Mayrhofer MT, Holub P, Wutte A, Litton JE (2016) BBMRI-ERIC: the novel gateway to biobanks. Bundesgesundheitsbl Gesundheitsforsch Gesundheitsschutz 59:379-384

66. Haslacher H, Szekeres T, Gerner M et al (2017) The effect of storage temperature fluctuations on the stability of biochemical analytes in blood serum. Clin Chem Lab Med 55:974-983

67. Chaigneau C, Cabioch T, Beaumont K, Betsou F (2007) Serum biobank certification and the establishment of quality controls for biological fluids: examples of serum biomarker stability after temperature variation. Clin Chem Lab Med 45:1390-1395

68. Malentacchi F, Ciniselli CM, Pazzagli M, Verderio P, Barraud L, Hartmann CC, Pizzamiglio S, Weisbuch S, Wyrich R, Gelmini S (2015) Influence of pre-analytical procedures on genomic DNA integrity in blood samples: the SPIDIA experience. Clin Chim Acta 440:205-210

69. Rainen L, Oelmueller U, Jurgensen S, Wyrich R, Ballas C, Schram J, Herdman C, Bankaitis-Davis D, Nicholls N, Trollinger D, Tryon V (2002) Stabilization of mRNA expression in whole blood samples. Clin Chem 48:1883-1890

70. Malentacchi F, Pazzagli M, Simi L, Orlando C, Wyrich R, Günther K, Verderio P, Pizzamiglio S, Ciniselli CM, Zhang H, Korenková V, Rainen L, Bar T, Kubista M, Gelmini S (2014) SPIDIA-RNA: second external quality assessment for the pre-analytical phase of blood samples used for RNA based analyses. PLoS One 9:e112293

71. Gündisch S, Hauck S, Sarioglu H, Schott C, Viertler C, Kap M, Schuster T, Reischauer B, Rosenberg R, Verhoef C, Mischinger HJ, Riegman P, Zatloukal K, Becker KF (2012) Variability of protein and phosphoprotein amounts in clinical tissue specimens during the preanalytical phase. J Proteome Res 11:5748-5762

72. Bernini P, Bertini I, Luchinat C, Nincheri P, Staderini S, Turano P (2011) Standard operating procedures for pre-analytical handling of blood and urine for metabolomics studies and biobanks. J Biomole NMR 49:231-243

73. Kaushik N, Green S (2014) Pre-analytical errors: their impact and how to minimize them. Med Lab Observ 46:22-26

74. Regulation (EU) $2017 / 746$ of the European Parliament and of the Council of 5 April 2017 on in vitro diagnostic medical devices and repealing Directive 98/79/EC and Commission Decision 2010/227/EU (https://eur-lex.europa.eu/eli/reg/2017/746/oj)

75. Paltiel L, Aarem J, Bækken S et al (2012) Biospecimen quality program in the biobank of the Norwegian Institute of Public Health. Norsk Epidemiol 21:225-229 
76. Lippi G, Chance JJ, Church S, Dazzi P, Fontana R, Giavarina D, Grankvist K, Huisman W, Kouri T, Palicka V, Plebani M, Puro V, Salvagno GL, Sandberg S, Sikaris K, Watson I, Stankovic AK, Simundic AM (2011) Preanalytical quality improvement: from dream to reality. Clin Chem Lab Med 49:1113-1126

77. Plebani M (2006) Errors in clinical laboratories or errors in laboratory medicine? Clin Chem Lab Med 44:750-759

78. Lippi G, Guidi GC, Mattiuzzi C, Plebani M (2006) Preanalytical variability: the dark side of the moon in laboratory testing. Clin Chem Lab Med 44:358-365

79. Grecu DS, Vlad DC, Dumitrascu V (2014) Quality indicators in the preanalytical phase of testing in a stat laboratory. Lab Med 45:74-81

80. Zaini R, Dahlawi HA, Siddiqi A (2016) Identification of the types and frequencies of pre-analytical errors in the clinical biochemistry laboratory: 1-year study at Hera'a General Hospital. Archiv Med 8:1

81. Kamlage B, Neuber S, Bethan B et al (2018) Impact of prolonged blood incubation and extended serum storage at room temperature on the human serum metabolome. Metabolites 8:pi:E6

82. Yang W, Chen Y, Xi C, Zhang R, Song Y, Zhan Q, Bi X, Abliz Z (2013) Liquid chromatography-tandem mass spectrometry-based plasma metabonomics delineate the effect of metabolites' stability on reliability of potential biomarkers. Anal Chem 85:2606-2610

83. Kamlage B, Maldonado SG, Bethan B, Peter E, Schmitz O, Liebenberg V, Schatz P (2014) Quality markers addressing preanalytical variations of blood and plasma processing identified by broad and targeted metabolite profiling. Clin Chem 60:399-412

84. Adams GP, Weiner LM (2009) Monoclonal antibody therapy of cancer. Nat Biotechnol 9:1147-1157

85. Hofmann M, Große-Hovest L, Nübling T, Pyż E, Bamberg ML, Aulwurm S, Bühring HJ, Schwartz K, Haen SP, Schilbach K, Rammensee HG, Salih HR, Jung G (2012) Generation, selection and preclinical characterization of an Fc-optimized FLT3 antibody for the treatment of myeloid leukemia. Leukemia 26:1228-1237

86. Nelson MH, Paulos CM (2015) Novel immunotherapies for hematologic malignancies. Immunol Rev 263:90-105

87. Seaman S, Zhu Z, Saha S, Zhang XM, Yang MY, Hilton MB, Morris K, Szot C, Morris H, Swing DA, Tessarollo L, Smith SW, Degrado S, Borkin D, Jain N, Scheiermann J, Feng Y, Wang Y, Li J, Welsch D, DeCrescenzo G, Chaudhary A, Zudaire E, Klarmann KD, Keller JR, Dimitrov DS, St. Croix B (2017) Eradication of tumors through simultaneous ablation of CD276/B7-H3-positive tumor cells and tumor vasculature. Cancer Cell 31:501-515

88. Hemminki A, Kellokumpu-Lehtinen PL (2006) Harmful impact of EU clinical trials directive. BMJ 332:501-502

89. Wang M, Zhao J, Zhang L, Wei F, Lian Y, Wu Y, Gong Z, Zhang S, Zhou J, Cao K, Li X, Xiong W, Li G, Zeng Z, Guo C (2017) Role of tumor microenvironment in tumorigenesis. J Cancer 8:761-773

90. Crotti S, Piccoli M, Rizzolio F, Giordano A, Nitti D, Agostini M (2017) Extracellular matrix and colorectal cancer: how surrounding microenvironment affects cancer cell behavior? J Cell Physiol 232:967-975

91. Gajewski TF, Schreiber H, Fu YX (2013) Innate and adaptive immune cells in the tumor microenvironment. Nat Immunol 14:1014-1022

92. Guldbrandsen KF, Hendel HW, Langer SW, Fischer B (2017) Nuclear molecular imaging strategies in immune checkpoint inhibitor therapy. Diagnostics 7:23

93. $\mathrm{He} \mathrm{JB}, \mathrm{Hu} \mathrm{Y}, \mathrm{Hu}$ MM, Li BL (2015) Development of PD-1/PD-L1 pathway in tumor immune microenvironment and treatment for nonsmall cell lung cancer. Sci Rep 5:13110

94. Dong YN, Sun Q, Zhang XW (2017) PD-1 and its ligands are important immune checkpoints in cancer. Oncotarget 8:2171-2186

95. Chatterjee S, Lesniak WG, Nimmagadda S (2017) Noninvasive imaging of immune checkpoint ligand PD-L1 in tumors and metastases for guiding immunotherapy. Mol Imaging 16(1):536012117718459

96. Bensch F, van der Veen EL, Lub-de Hooge MN, Jorritsma-Smit A, Boellaard R, Kok IC, Oosting SF, Schröder CP, Hiltermann TJN, van der Wekken AJ, Groen HJM, Kwee TC, Elias SG, Gietema JA, Bohorquez SS, de Crespigny A, Williams SP, Mancao C, Brouwers $\mathrm{AH}$, Fine BM, de Vries EGE (2018) ${ }^{89} \mathrm{Zr}$-atezolizumab imaging as a non-invasive approach to assess clinical response to PD-L1 blockade in cancer. Nat Med 24:1852-1858
97. Hammoud DA (2016) Molecular imaging of inflammation: current status. J Nucl Med 57:1161-1165

98. Ponomarev V (2017) Advancing immune and cell-based therapies through imaging. Mol Imaging Biol 19:379-384

99. Ebert PJR, Cheung J, Yang Y, McNamara E, Hong R, Moskalenko M, Gould SE, Maecker H, Irving BA, Kim JM, Belvin M, Mellman I (2016) MAP kinase inhibition promotes $\mathrm{T}$ cell and anti-tumor activity in combination with PD-L1 checkpoint blockade. Immunity 44:609-621

100. Hettich M, Braun F, Bartholoma MD, Schirmbeck R, Niedermann G (2016) High-resolution PET imaging with therapeutic antibodybased PD-1/PD-L1 checkpoint tracers. Theranostics 6:1629-1640

101. Antonios JP, Soto H, Everson RG, Moughon DL, Wang AC, Orpilla J, Radu C, Ellingson BM, Lee JT, Cloughesy T, Phelps ME, Czernin J, Liau LM, Prins RM (2017) Detection of immune responses after immunotherapy in glioblastoma using PET and MRI. Proc Natl Acad Sci U S A 114:10220-10225

102. Radu CG, Shu CJ, Nair-Gill E, Shelly SM, Barrio JR, Satyamurthy N, Phelps ME, Witte ON (2008) Molecular imaging of lymphoid organs and immune activation by positron emission tomography with a new $\left[{ }^{18} \mathrm{~F}\right]$-labeled 2 -deoxycytidine analog. Nat Med 14:783-788

103. Namavari M, Chang YF, Kusler B, Yaghoubi S, Mitchell BS, Gambhir SS (2011) Synthesis of 2'-deoxy-2'-[ ${ }^{18}$ F]fluoro-9-beta-Darabinofuranosylguanine: a novel agent for imaging T-cell activation with PET. Mol Imaging Biol 13:812-818

104. Tavare R, Escuin-Ordinas H, Mok S, McCracken MN, Zettlitz KA, Salazar FB, Witte ON, Ribas A, Wu AM (2016) An effective immuno-PET imaging method to monitor CD8-dependent responses to immunotherapy. Cancer Res 76:73-82

105. ClinicalTrials.gov. ${ }^{89} \mathrm{Zr}$-Df-IAB22M2C PET/CT in patients with selected, metastatic solid malignancies or Hodgkin's lymphoma. https://clinicaltrials.gov/ct2/show/NCT03107663 (accessed 11.5.2018)

106. Ehlerding EB, England CG, Majewski RL, Valdovinos HF, Jiang D, Liu G, McNeel DG, Nickles RJ, Cai W (2017) ImmunoPET imaging of CTLA-4 expression in mouse models of non-small cell lung cancer. Mol Pharm 14:1782-1789

107. Zheleznyak A, Ikotun OF, Dimitry J, Frazier WA, Lapi SE (2013) Imaging of CD47 expression in xenograft and allograft tumor models. Mol Imaging 12:7290.2013.00069. https://doi.org/10.2310/ 7290.2013.00069

108. Griessinger CM, Maurer A, Kesenheimer C, Kehlbach R, Reischl G, Ehrlichmann W, Bukala D, Harant M, Cay F, Brück J, Nordin R, Kohlhofer U, Rammensee HG, Quintanilla-Martinez L, Schaller M, Röcken M, Pichler BJ, Kneilling M (2015) 64Cu antibody-targeting of the T-cell receptor and subsequent internalization enables in vivo tracking of lymphocytes by PET. Proc Natl Acad Sci U S A 112:1161-1166

109. Mall S, Yusufi N, Wagner R, Klar R, Bianchi H, Steiger K, Straub M, Audehm S, Laitinen I, Aichler M, Peschel C, Ziegler S, Mustafa M, Schwaiger M, D'Alessandria C, Krackhardt AM (2016) ImmunoPET imaging of engineered human $\mathrm{T}$ cells in tumors. Cancer Res 76:4113-4123

110. Vag T, Gerngross C, Herhaus P, Eiber M, Philipp-Abbrederis K, Graner FP, Ettl J, Keller U, Wester HJ, Schwaiger M (2016) First experience with chemokine receptor CXCR4-targeted PET imaging of patients with solid cancers. J Nucl Med 57:741-746

111. Meletta R, Müller Herde A, Dennler P, Fischer E, Schibli R, Krämer SD (2016) Preclinical imaging of the co-stimulatory molecules CD80 and CD86 with indium-111-labeled belatacept in atherosclerosis. EJNMMI Res 6:1

112. Betzel T, Muller C, Groehn V et al (2013) Radiosynthesis and preclinical evaluation of $3^{\prime}$-Aza- $2^{\prime}-\left[{ }^{18} \mathrm{~F}\right]$ fluorofolic acid: a novel PET radiotracer for folate receptor targeting. Bioconjug Chem 24:205214

113. Ayala-Lopez W, Xia W, Varghese B, Low PS (2010) Imaging of atherosclerosis in apoliprotein $\mathrm{E}$ knockout mice: targeting of a folateconjugated radiopharmaceutical to activated macrophages. J Nucl Med 51:768-774

114. Schreiber RD, Old LJ, Smyth MJ (2011) Cancer immunoediting: integrating immunity's roles in cancer suppression and promotion. Science 331:1565-1570

115. Le DT, Uram JN, Wang $\mathrm{H}$ et al (2015) PD-1 blockade in tumors with mismatch-repair deficiency. N Engl J Med 372:2509-2520 
116. Snyder A, Makarov V, Merghoub T, Yuan J, Zaretsky JM, Desrichard A, Walsh LA, Postow MA, Wong P, Ho TS, Hollmann TJ, Bruggeman C, Kannan K, Li Y, Elipenahli C, Liu C, Harbison CT, Wang L, Ribas A, Wolchok JD, Chan TA (2014) Genetic basis for clinical response to CTLA-4 blockade in melanoma. N Engl J Med 371:2189-2199

117. Reck M, Rodríguez-Abreu D, Robinson AG, Hui R, Csőszi T, Fülöp A, Gottfried M, Peled N, Tafreshi A, Cuffe S, O'Brien M, Rao S, Hotta K, Leiby MA, Lubiniecki GM, Shentu Y, Rangwala R, Brahmer JR, KEYNOTE-024 Investigators (2016) Pembrolizumab versus chemotherapy for PD-L1-positive non-small-cell lung cancer. N Engl J Med 375:1823-1833

118. Younes A, Santoro A, Shipp M, Zinzani PL, Timmerman JM, Ansell S, Armand P, Fanale M, Ratanatharathorn V, Kuruvilla J, Cohen JB, Collins G, Savage KJ, Trneny M, Kato K, Farsaci B, Parker SM, Rodig S, Roemer MGM, Ligon AH, Engert A (2016) Nivolumab for classical Hodgkin's lymphoma after failure of both autologous stemcell transplantation and brentuximab vedotin: a multicentre, multicohort, single-arm phase 2 trial. Lancet Oncol 17:1283-1294

119. Bergmann M, Romirer I, Sachet M, Fleischhacker R, García-Sastre A, Palese P, Wolff K, Pehamberger H, Jakesz R, Muster T (2001) A genetically engineered influenza A virus with ras-dependent oncolytic properties. Cancer Res 61:8188-8193

120. Kaufman HL, Kohlhapp FJ, Zloza A (2015) Oncolytic viruses: a new class of immunotherapy drugs. Nat Rev Drug Discov 14:642-662

121. Schork NJ (2015) Personalized medicine: time for one-person trials. Nature 520:609-611

122. Bach PB (2009) Limits on Medicare's ability to control rising spending on cancer drugs. N Engl J Med 360:626-633

123. Drummond MF, Sculpher MJ, Claxton K, Stoddart GL, Torrance GW (2015) Methods for the economic evaluation of health care programmes, 4th edn. Oxford: Oxford University Press, Oxford

124. Soares MO, Walker S, Palmer SJ, Sculpher MJ (2018) Establishing the value of diagnostic and prognostic tests in health technology assessment. Med Decis Mak 38:495-508

125. Claxton K, Palmer S, Longworth L, Bojke L, Griffin S, McKenna C, Soares M, Spackman E, Youn J (2012) Informing a decision framework for when NICE should recommend the use of health technologies only in the context of an appropriately designed programme of evidence development. Health Technol Assess 16:1323

126. Drucker E, Krapfenbauer K (2013) Pitfalls and limitations in translation from biomarker discovery to clinical utility in predictive and personalised medicine. EPMA J 4:7

127. Salari K (2009) The dawning era of personalized medicine exposes a gap in medical education. PLoS Med 6:e1000138

128. National Research Council (2011) Toward precision medicine: building a knowledge network for biomedical research and a new taxonomy of disease. The National Academies Press, Washington, DC. https://doi.org/10.17226/13284

129. Faria R, Soares MO, Spackman E, Ahmed HU, Brown LC, Kaplan R, Emberton M, Sculpher MJ (2018) Optimising the diagnosis of prostate cancer in the era of multi-parametric magnetic resonance imaging: a cost-effectiveness analysis based on the Prostate MR Imaging Study (PROMIS). Eur Urol 73:23-30
130. Pletscher M, Walker SM, Moschetti K, Pinget C, Wasserfallen JB, Greenwood JP, Schwitter J, Girardin FR (2016) Cost-effectiveness of functional cardiac imaging in the diagnostic work-up of coronary heart disease. Eur Heart J Qual Care Clin Outcomes 2:201-207

131. Farrar D, Simmonds M, Griffin S, Duarte A, Lawlor DA, Sculpher M, Fairley L, Golder S, Tuffnell D, Bland M, Dunne F, Whitelaw D, Wright J, Sheldon TA (2016) The identification and treatment of women with hyperglycaemia in pregnancy: an analysis of individual participant data, systematic reviews, meta-analyses and an economic evaluation. Health Technol Assess 20:1-348

132. Saramago P, Yang H, Llewellyn A, Palmer S, Simmonds M, Griffin S (2018) High-throughput, non-invasive prenatal testing for fetal RHD genotype to guide antenatal prophylaxis with anti-D immunoglobulin: a cost-effectiveness analysis. BJOG 125:1414-1422

133. Ahn AC, Tewari M, Poon CS, Phillips RS (2006) The clinical applications of a systems approach. PLoS Med 3:e209

134. Auffray C, Chen Z, Hood L (2009) Systems medicine: the future of medical genomics and healthcare. Genome Med 1:2

135. Capobianco E (2012) Ten challenges for systems medicine. Front Genet 3:193

136. Capobianco E (2013) Dynamic networks in systems medicine. Front Genet 3:185

137. Federoff HJ, Gostin LO (2009) Evolving from reductionism to holism: is there a future for systems medicine? JAMA 302:994-996

138. Fischer T, Brothers K, Erdmann P et al (2016) Clinical decisionmaking and secondary findings in systems medicine. BMC Med Ethics 17:32

139. Wolkenhauer O, Auffray C, Jaster R, Steinhoff G, Dammann O (2013) The road from systems biology to systems medicine. Pediatr Res 73:502-507

140. Zhao Z, Shen B, Lu X et al (2013) Translational biomedical informatics and computational systems medicine. Biomed Res Int 2013:237465

141. Gomez-Cabrero D, Menche J, Cano I et al (2014) Systems medicine: from molecular features and models to the clinic in COPD. J Transl Med 12(Suppl 2):S4

142. Schleidgen S, Fernau S, Fleischer H, Schickhardt C, Oßa AK, Winkler EC (2017) Applying systems biology to biomedical research and health care: a précising definition of systems medicine. BMC Health Serv Res 17:761

143. Howard SA, Krajewski KM, Weissman BN, Seltzer SE, Ramaiya $\mathrm{NH}$, van den Abbeele AD (2015) Cancer imaging training in the 21st century: an overview of where we are, and where we need to be. J Am Coll Radiol 12:714-720

144. Wang E, Cho WCS, Wong SCC, Liu S (2017) Disease biomarkers for precision medicine: challenges and future opportunities. Genomics Proteomics Bioinformatics 15:57-58

Publisher's Note. Springer Nature remains neutral with regard to jurisdictional claims in published maps and institutional affiliations. 